\title{
Astragalar and calcaneal morphology of the middle Eocene primate Anchomomys frontanyensis (Anchomomyini): implications for early primate evolution
}

Judit Marigón ${ }^{1,2 \star}$, Imma Roig $^{2}$, Erik R. Seiffert ${ }^{3}$, Salvador Moyà-Solà4 ${ }^{4}$ Doug M. Boyer ${ }^{1}$

${ }^{1}$ Department of Evolutionary Anthropology, Duke University, Durham, North Carolina, United States of America.

2 Institut Català de Paleontologia Miquel Crusafont (ICP), Universitat Autònoma de Barcelona, Edifici Z, Campus UAB, 08193 Cerdanyola del Vallès, Barcelona, Spain.

${ }^{3}$ Department of Anatomical Sciences, Stony Brook University, Stony Brook, New York, United States of America.

${ }^{4}$ ICREA at the Institut Català de Paleontologia Miquel Crusafont (ICP), Universitat Autònoma de Barcelona, Edifici Z, Campus UAB, 08193 Cerdanyola del Vallès, Barcelona, Spain.

${ }^{\star}$ Corresponding author

Corresponding Author Address: judit.marigo@duke.edu; Department of Evolutionary Anthropology, Duke University, 01AA Biological Sciences Building, 130 Science Drive, Durham, NC 27708, United States of America; Campus Box 90383; Phone: 919-660-7392; Fax: 919-6607348

\section{Keywords}

Astragalus, Calcaneus, Postcranial, Sant Jaume de Frontanyà, Southern Pyrenean basins, Spain, Distal calcaneal elongation, Leaping, Robiacian

\section{Abstract}

Astragali and calcanei of Anchomomys frontanyensis, a small adapiform from the middle Eocene of Sant Jaume de Frontanyà (Southern Pyrenean basins, northeastern Spain) are described in detail. Though these bones have been known for some time, they have never been carefully analysed in a context that is comprehensively comparative, quantitative, considers sample variation (astragalus $n=4$; calcaneus $n=16$ ), and assesses the phylogenetic significance of the material in an explicit cladistic context, as we do here. Though these bones are isolated, regression analyses provide the first formal statistical support for attribution to $A$. frontanyensis. 
The astragalus presents features similar to those of the small stem strepsirrhine Djebelemur from the middle Eocene of Tunisia, while the calcaneus more closely resembles those of the basal omomyiform Teilhardina. The new phylogenetic analyses that include Anchomomys' postcranial and dental data recover anchomomyins outside of the adapiform clade, and closer to djebelemurids, azibiids, and crown strepsirrhines. The small size of $A$. frontanyensis allows comparison of similarly small adapiforms and omomyiforms (haplorhines) such that observed variation has more straightforward implications for function. Previous studies have demonstrated that distal calcaneal elongation is reflective of leaping proclivity when effects of body mass are appropriately accounted for; in this context, $A$. frontanyensis has calcaneal elongation suggesting a higher degree of leaping specialization than other adapiforms and even some early omomyiforms. Moreover, comparison to a similarly-sized early adapiform from India, Marcgodinotius (which shows no calcaneal elongation) confirms that high distal calcaneal elongation in $A$. frontanyensis cannot be simply explained by allometric effects of small size compared to larger adapiform taxa. This pattern is consistent with the idea that significant distal calcaneal elongation evolved at least twice in early euprimates, and that early primate niche space frequently included demands for increased leaping specialization.

\section{Introduction}

Comprehension of ecological factors driving primate origins and early evolution is an important goal of many researchers (e.g., Cartmill, 1972; 1974a,b; 1992; Sussman and Raven, 1978; Bloch et al., 2007; see references in Ravosa and Dagosto, 2007). Because of the contingent nature of macroevolution, a better understanding of a clade's early history yields insight into later events as well. Reconstructing morphological changes in early primate evolution is the first step for understanding evolutionary ecological dynamics in early primates. More complete representation of more fossil taxa aids in both phylogenetic reconstruction and in developing hypotheses of functional-adaptive transitions (e.g., Strait and Grine, 2004).

Because dental remains are more common than crania or postcrania for Eocene primates, they have been the subject of many studies on systematics and phylogenetics. Little by little, knowledge of the postcranial skeleton has improved, but it is still relatively poor, such that many debates focus on questions requiring crania and postcrania (e.g., is Eosimias an anthropoid? Is Darwinius an anthropoid?). As recently demonstrated by the case of Algeripithecus and Azibius, increasing skeletal representation can change a diagnosis from anthropoid to strepsirrhine and plesiadapiform to strepsirrhine, respectively (Marivaux et al., 
2003). In Europe, Eocene postcranials that can be confidently associated with dental taxa are rare. The majority of known specimens are Phosphorites du Quercy adapines (e.g., Dagosto, 1983; Godinot and Jouffroy, 1984; Godinot, 1989, 1991, 1992; Godinot and Beard, 1991; Bacon and Godinot, 1998; Boyer et al., 2013a,b), rare elements of microchoerines (Schmid, 1979; Godinot and Dagosto, 1983), a partial skeleton of Nannopithex (Thalmann, 1994), and a handful of "cercamoniines" from the Lagerstätten deposits of Messel (e.g., Franzen, 1987, 2000; Franzen et al., 2009; Boyer et al., 2013a,b) and Geiseltal (Thalmann, 1994; Thalmann et al., 1989; Boyer et al., 2013a, b). This can be contrasted with the situation in North America where a great deal is known about many of the various notharctid and omomyiform species that occur there. As a result, the adaptive landscape and clade-specific differences apparent there have come to dominate perspectives on the tendencies and dynamics of early primate evolution (Rose, 1994).

The Robiacian (MP14-15) locality of Sant Jaume de Frontanyà-3C (SJF-3C, Bellmunt Formation, Barcelona, NE Spain) yields both a rich sample of primate teeth (Minwer-Barakat et al., 2010; Marigó et al., 2011) and an exceptional collection of postcranial bones of adapiforms and omomyiforms (Moyà-Solà and Köhler, 1993; Moyà-Solà et al., 2011). This site therefore presents unusual potential for improving knowledge of European early primates. Here, the following three different primate taxa have been recognised: two adapiforms (Adapis sp. and Anchomomys frontanyensis Marigó et al., 2011) and one omomyiform (Pseudoloris pyrenaicus Minwer-Barakat et al., 2010).

The relationships of the genus Anchomomys and its bearing on the strepsirrhine affinities of adapiforms have been debated (Stehlin, 1916; Simons, 1962; Gingerich, 1977; Tattersall and Schwartz, 1983; Godinot, 1988; Gheerbrant et al., 1993; Rasmussen and Nekaris, 1998; Rose et al., 2009; Seiffert et al., 2009; Tabuce et al., 2009). So far, however, no detailed study of the postcranials of Anchomomys has been published though Moyà-Solà and Köhler (1993) reported the existence of such material and provided an illustration of an astragalus (IPS-7712) and Moyà-Solà et al. (2011) included a brief description, illustration and certain measurements of the calcaneus IPS-7748. Thus, the information that postcranials might provide about the locomotor behavior and phylogenetic position of anchomomyins remains largely untapped.

In the present study, we provide, for the first time, a detailed description of the astragali and calcanei of Anchomomys frontanyensis, which were previously cited in Moyà-Solà and Köhler (1993), Roig et al. (2009) and Moyà-Solà et al. (2011). The very small size of this adapiform allows us to directly compare adapiform and omomyiform postcranial remains of 
similar size, thus avoiding the potential effect of body mass on bone shape and proportions (Moyà-Solà et al., 2011; Boyer et al., 2013a). It also allows a narrow allometric approach (cf. Gilbert and Rossie, 2007) within which locomotor diversity in small adapiforms can be assessed, as similar-sized djebelemurids and azibiids are also represented by astragali. This is critical when assessing functional/adaptive tendencies and inferring ancestral morphotypes for early primates. It also may be an important issue when tarsal characters are used to infer the phylogenetic relationships between Eocene primate and extant taxa (Gebo et al., 2001). For instance, the omomyiforms are often described as having greater calcaneal elongation and leaping tendencies than adapiforms (e.g., Rose, 1994). However, studies of Anchomomys have suggested that this distinction might be an artefact of small size. Anchomomys has greater proportional calcaneal elongation (Roig et al., 2009; Moyà-Solà et al., 2011) than some similarly sized omomyiforms and also greater allometrically corrected elongation (which correlates with leaping tendency) than any other adapiform and some early omomyiforms (Boyer et al., 2013a).

We address four questions in the present study: (1) what does new postcranial information indicate about the phylogenetic position of Anchomomys?; (2) what does new postcranial information suggest about previously proposed hypotheses about differences between large adapiform and small omomyiform tarsal morphology?; (3) what does the astragalus suggest about functional/behavioural tendencies of Anchomomys relative to recent claims based on the calcaneus alone by Moyà-Solà et al. (2011) and Boyer et al. (2013a); and (4) what does the new information about phylogeny and morphological patterns provided by these bones reveal about early primate evolution?

\section{Material and methods}

Sample and attribution

All new material considered here comes from level 3C of the fossil site of Sant Jaume de Frontanyà (SJF-3C) after sampling and screen-washing three tons of sediments in the 1990s. The attribution of some tarsal bones to Anchomomys frontanyensis was originally supported by the fact that, based on dental remains, $A$. frontanyensis is the most abundant primate found in SJF-3C and consequently most of the adapiform postcranial remains can be attributed to this taxon (Moyà-Solà and Köhler, 1993). In addition, Adapis sp. and Pseudoloris pyrenaicus (a large-sized and a small-sized species, respectively) had a sufficiently different body size to be

recognized, and their postcranial remains have been identified using both size differences and 
morphological criteria. Furthermore, neither dental nor postcranial specimens of omomyiforms of a comparable size to $A$. frontanyensis have been found in the site. Finally, we plot astragalar trochlear width and calcaneal cuboid facet area against mandibular second molar $(\mathrm{m} / 2)$ length using comparative data provided by Boyer and Seiffert (2013), Boyer et al. (2013a) and Winchester et al. (2014) showing that the astragalar trochlea and cuboid facet area predict $\mathrm{m} / 2$ sizes that include dimensions of $A$. frontanyensis, but exclude Adapis sp. and $P$. pyrenaicus (Fig. 1).

Two complete and well-preserved (IPS-7712 and IPS-7713), and two fragmented and quite damaged astragali (IPS-7750 and IPS-7796) were available for the study. One complete calcaneus (although slightly damaged at the distal part; IPS-7748), and 15 fragmentary specimens (IPS-7745, IPS-7749, IPS-7751, IPS-7752, IPS-7798, IPS-7799-IPS-7802, IPS7984-IPS-7989) were also available. More information on each specimen is available in Table 1 , and all scanned specimens can be seen in Figure 2.

\section{Casting and scanning}

To aid in description, measurement and distribution of anatomical information, all specimens presenting significant anatomical information and described here were microCT scanned at Duke University's Shared Materials Instrumentation Facility using a Nikon XTH 225 ST scanner at at 9.9-6.5 micron resolution with isometric voxels. Scanning details are available for each specimen (Table 1). Furthermore, specimens are all available on www.morphosource.org for viewing and download.

The postcranial remains from Sant Jaume de Frontanyà-3C were not scanned directly because they often contain a strongly attenuating precipitate within trabecular pore space and medullary cavities that yields images rendered unusable due to beam hardening. Instead we casted the specimens and scanned the casts. Instead of generating a full cast with a two piece mold, we made two overlapping one-piece molds, which together represented more than 100\% of the anatomy of each bone. Of the available calcanei specimens, seven of them were not even casted or scanned because they didn't have any of the facets complete and useful for measuring (IPS-7752, IPS-7800, IPS-7802, IPS-7985, IPS-7988, IPS-7989), although they were used for comparisons.

\section{Surface files}


The images obtained from microCT scans were reconstructed using the Nikon ${ }^{\circledR}$ program CT Pro 3D, and then the surface files were made using the program Avizo 8 (Visualization Sciences Group, 2009). Once the surface files were obtained, the program Geomagic Studio 2013 (3D Systems, 2013) was used to merge the surface files representing the two halves of each specimen, as well as for smoothing the final surfaces. This method of combining two "more-than-half" casts has the benefit of producing scans from casts without a flash-line and the potential deformation it represents.

\section{Terminology and measurements}

Supplementary Online Material (SOM) Figure 1 shows the terminology used in the text. The astragali and calcanei attributed to $A$. frontanyensis have been measured from surface scans following the methodology used by Boyer et al. (2010) and Marivaux et al. (2011) for the astragali and that of Gladman et al. (2013) for the calcanei. As well, measurements of Boyer and Seiffert (2013) were also taken. Moreover, we have measured astragali and calcanei of $A$. frontanyensis as well as all the other specimens used for comparisons as shown in Figure 3.Linear measurements were taken with the 2D or 3D tool in Avizo 8, depending on the methodology, and surface area measurements were taken using Geomagic Studio 2013.

\section{Comparative sample}

Since $A$. frontanyensis was defined as a cercamoniine notharctid based on the morphology of its dentition (Marigó et al., 2011), its astragalus and calcaneus are compared with other notharctids such as Notharctus, Cantius and Smilodectes. In the same publication, a phylogenetic analysis was performed, and two different results were obtained, placing $A$. frontanyensis in a close relationship with either djebelemurids or asiadapines. Hence, its tarsal bones are here also compared to Djebelemur, Azibius, Asiadapis and Marcgodinotius.

In addition, $A$. frontanyensis is also compared to the extant cheirogaleids Cheirogaleus, Microcebus and Mirza, since previous works have noted similarities between Cheirogaleus and A. frontanyensis (Roig and Moyà-Solà, 2011).

Finally, because of the already mentioned small size of $A$. frontanyensis, as well as its distal calcaneal elongation, both similar to omomyiforms, $A$. frontanyensis is here also compared to the omomyiforms Teilhardina, Omomys and Necrolemur. Moreover, it is also 
compared to similar-sized eosimiids, here considered to be the most primitive stem anthropoids represented by tarsals.

Institutional abbreviations

AMNH, American Museum of Natural History, New York, NY, USA; BFI, HGL, UM/HGL, ISE, Institut des Sciences de l'Évolution, Université Montpellier-2, Montpellier, France; DPC, Duke Lemur Center Division of Fossil Primates, Durham, NC, USA; GU, H.N.B. Garhwal University, Srinagar, Uttarakhand, India; IPS, Institut de Paleontologia de Sabadell (currentlyInstitut Català de Paleontologia Miquel Crusafont), Sabadell, Barcelona, Spain; IRSNB, Institut Royal des Sciences Naturelles de Belgique, Brussels, Belgium; IVPP, Institute of Vertebrate Paleontology and Paleoanthropology, Chinese Academy of Sciences, Beijing, China; NHMB, Naturhistorisches Museum Basel, Basel, Switzerland; PMZ, Paleontology Museum of the University of Zürich, Zürich, Switzerland; UCM, University of Colorado Museum of Natural History, Boulder, CO; UF, University of Florida, Florida Museum of Natural History, Gainesville, FL, USA; UM, University of Michigan, Ann Arbor, Michigan; USGS, U.S. Geological Survey, Denver, Colorado.

\section{Phylogenetic analysis}

Phylogenetic analyses were run using an augmented version of a character-taxon matrix of living and extinct primates and euarchontan outgroups that was most recently employed by Boyer et al. (2013a). The matrix analyzed here (SOM File 1) includes 391 characters and 106 taxa, and includes recently described material of Djebelemur (Marivaux et al. 2013) and the anchomomyins Mazateronodon and Nievesia (Marigó et al. 2010, 2013), in addition to that of $A$. frontanyensis [Marigó et al. 2011, including characters from the navicular of that species (Marigó et al. 2014)]. We have also scored the oldest European adapine, middle Eocene Leptadapis ruetimeyeri; one of its congeners, Leptadapis priscus; and the oldest known adapiform, Cantius ralstoni. Two parsimony analyses were run in PAUP 4.0b10, one in which premolars were not allowed to re-evolve following a previous loss, and one with no such constraint. In both analyses some multistate characters were treated as ordered, and those with polymorphisms scored as intermediate states were scaled to a half-step so that transitions between adjacent "fixed" states in morphoclines were equal to one full step. Parsimony analyses were run for 10,000 replicates with random addition sequence and the tree-bisection- 
reconnection branch-swapping algorithm; clade support was estimated by bootstrap analysis in PAUP (1,000 pseudoreplicates). A single Bayesian analysis was run in MrBayes 3.2.2 (Ronquist et al., 2012) with all characters unordered (with flat priors, gamma-distributed rate variation across characters, and the Mk model for morphological data; the analysis was run on the CIPRES server (Miller et al., 2010) for 50 million MCMC generations, sampling every 1000 generations, with the first $25 \%$ of samples discarded as "burn-in"), and summarized using the "allcompat" option (majority rule tree plus compatible groups). All of the analyses were constrained by a molecular scaffold (using a constraint tree in PAUP (SOM File 2), and partial constraint commands in MrBayes).

\section{Results}

\section{Description}

$\underline{\text { Astragulus }}$ The body of the astragalus has a long and narrow trochlea (MTRW/TRL $=0.73$, see Table 2 for astragalar measurements and indices following Boyer et al. [2010], Boyer and Seiffert [2013] and Marivaux et al. [2011]), and it is tall in relation to both the trochlear width and length (HT/MTRW=1.41; HT/TRL=1.03 in Table 2). Dorsally, the medial rim follows the proximodistal orientation of the trochlear groove, whereas the lateral rim looks a little bit more oblique, diverging more laterally from the medial rim towards the distal end of the trochlea, so that the trochlea is more mediolaterally constricted at its proximal end. The trochlear rims are of similar height, although the lateral one is sharper and slightly higher than the medial one, and the trochlear groove located between them is shallow. Proximally, the trochlea has a welldeveloped posterior trochlear shelf, with a groove for the flexor fibularis tendon in a lateral position. Distally, the medial rim seems to extend onto the neck until it reaches a transverse rim of bone on the medial side of the neck (Fig. 4, arrow 1), although no squatting facet is present. There is no sign of a superior astragalar foramen in the vicinity of the proximolateral margin of the lateral tibial facet.

The astragalar neck is slightly deviated medially (mean neck angle for two specimens is $18.80^{\circ}$ ) relative to the proximodistal axis of the trochlea. Mean neck length is $3.51 \mathrm{~mm}$ and represents $50.5 \%$ of total astragalar length (NL/TL=0.51 in Table 2). On the dorsolateral side of the neck, just proximal to the navicular facet, there is a well-developed tubercle that serves for the attachment of the talo-ectocuneiform ligament (Gregory, 1920; Rose et al., 2009). 
The astragalar head is ovoid in distal view, being broad relative to its height (HW/HHT=1.24 in Table 2), with an oblique long axis oriented dorsomedially. The navicular facet is more developed dorsolaterally than dorsomedially. The navicular facet is sometimes completely confluent with the sustentacular facet, and sometimes they become fused on only the medial side of the plantar aspect of the neck while they are separated on the lateral side. However, even when they are fused, an indentation in their limit of confluence can be seen laterally. Moreover, the navicular facet on the head of the astragalus is connected with the neck tubercle for the attachment of the talo-ectocuneiform ligament in $A$. frontanyensis. The spring ligament (plantar calcaneonavicular ligament) facet is also confluent with the sustentacular and the navicular facets.

The medial tibial facet of the astragalus forms an angle of $79.6^{\circ}$ with the lateral tibial facet (see Table 2, measurement 21). The medial tibial facet takes up a little bit more than half of the medial side of the astragalar body. On one specimen (IPS-7713), the medial tibial facet does not extend far onto the neck, and shows little or no distal curvature, while another specimen (IPS-7712) shows a more curved distal extension of the facet (i.e., a weak "cotylar fossa"); the latter is obscured by breakage but a small sliver of the most distal part of the medial tibial facet is preserved and faces proximomedially. Proximal to the medial tibial facet there is a weak groove for the attachment of the posterior talotibial ligament (part of the deltoid ligament). The dorsal part of the medial tibial facet of $A$. frontanyensis projects a little bit more medially than the central part. Moreover, it presents a protuberance along its plantar side that projects medially (Fig. 4, arrow 2).

The lateral tibial facet forms an angle of $108.5^{\circ}$ with the fibular facet following the protocol of Boyer and Seiffert (2013) (Table 2, FFS). Using the measurement protocol from Boyer et al. (2010) (representing a more preliminary approach) the facet slope is more obtuse $111.7^{\circ}$ (see Table 2, measurement 24). Both methods for measuring the slope of the fibular facet confirm that it is obliquely oriented and slopes outward from the lateral trochlear rim, forming the prominently pointed projection of the lateral astragalar process. Proximal to the fibular facet there is a well-defined and deeply-excavated fossa for the attachment of the posterior talofibular ligament.

On the plantar side of the astragalus, the ectal facet is concave, relatively broad, constricted near the central part, proximodistally elongated and obliquely oriented. The ectal facet of IPS-7796 seems to be narrower, but poor preservation of this bone renders the observation tentative. The sustentacular facet is convex, oriented proximodistally, and faces somewhat medially. It presents substantial variability in its proximodistal length. 
A wide and moderately deep astragalar sulcus separates both the ectal and the sustentacular facets. The astragalar sulcus, together with the calcaneal sulcus, housed the interosseous talocalcaneal ligament.

In sum, the astragalus of $A$. frontanyensis presents a morphology typical among adapiform euprimates, including the long and narrow trochlea, a high astragalar body in relation to both trochlear width and length, a shallow trochlear groove, a long and medially-angled neck, an ovoid astragalar head, a sustentacular facet confluent with the navicular facet, and a welldefined lateral tibial facet that extends slightly onto the neck of the astragalus (Godinot and Dagosto, 1983; Gebo, 1988; Rose et al., 2009). Moreover, it presents derived features typically characterizing many extant strepsirrhines and adapiforms (Beard et al., 1988; Williams et al., 2010), including a laterally sloped fibular facet, a laterally positioned groove for the tendon of flexor fibularis, and a large posterior trochlear shelf.

Calcaneus One of the most outstanding features of material attributed to $A$. frontanyensis is the elongated and slender calcaneus. This tarsal bone is long and narrow (CW/CL $=0.34$, see Table 3 for calcaneal measurements and indices following Gladman et al., 2013; Fig. 4), and its marked elongation is mainly due to the significant length of its distal part, which comprises 55\% of total calcaneal length ( $D L / C L=0.55$ in Table 3 ). The proximal end of the tuber calcanei is ovoid, with a pointed dorsolateral corner, and presents a dorsoplantarly convex surface for the attachment of the calcaneal tendon. The dorsal projection of the heel reaches the level of the medial side of the ectal facet, which is common for adapiforms, omomyiforms and some extant strepsirrhines (Gladman et al., 2013). The proximal end of the tuber calcanei curves slightly medially. Along the medial side of the bone, beginning at the sustentacular facet, there is a groove for the tendon of the flexor fibularis. The ectal facet is convex, longer than wide (EFW/EFL=0.52 in Table 3), proximodistally oriented, and small in relation to calcaneal length (EFL/CL=0.26 in Table 3). The calcaneal sulcus, which separates the ectal and sustentacular facets, is narrow and shallow. The sustentacular facet is slightly concave, generally rounded (except for specimen IPS-7984, which is not very well-preserved), and faces distolaterally.

The peroneal tubercle is moderately developed and is situated at the proximodistal level of the distal half of the ectal facet (in most specimens) and very close to the level of the confluence of the ectal facet and the distal part of the calcaneus (in specimen IPS-7984). It presents as a diffuse swelling, rather than an abrupt tubercle. On the peroneal tubercle a dorsal groove for the fibularis brevis tendon is visible, as is a ventral groove for the fibularis longus 
tendon. The plantar edge of the calcaneus is quite straight. Medioplantarly, on the distal end, the calcaneus of $A$. frontanyensis shows a prominent anterior plantar tubercle (the site of attachment of the plantar calcaneocuboid ligaments). Though the most complete calcaneus has a damaged cuboid facet, the cuboid facet morphology can be observed in the specimens IPS7745 and IPS-7799: it is concave and fan-shaped (CFW/CFH=1.42 in Table 3), showing a rather deep well-developed articular pit that is located at the level of the anterior plantar tubercle (Fig. 4).

Comparisons with astragali of other living and extinct primates

For a complete list of the specimens used for comparisons see SOM Table 1. See SOM Table 2 for mean astragalar measurements of each genus used for comparisons as well as $A$. frontanyensis. For box plots of astragalar indices of all the genera see Figure 5.

The astragali of $A$. frontanyensis are about the same size as that of Azibius, and close to those of Cheirogaleus medius, Marcgodinotius, Mirza, Necrolemur, and Omomys (Fig. 6). The astragali of Asiadapis, Cantius, Notharctus, Smilodectes, and Cheirogaleus major are larger than those of $A$. frontanyensis. On the other hand, the astragali of Djebelemur, Eosimias, Microcebus, and Teilhardina are smaller than that of $A$. frontanyensis.

Relative to overall astragalar length, the astragalar body length of $A$. frontanyensis exhibits a range of values that overlap with those of Asiadapis and most Cheirogaleus, as well as some specimens of Microcebus, Cantius, Notharctus, Teilhardina, Omomys, and one specimen of Eosimias (IVPP V 12303). Azibius, Djebelemur, and most specimens of Microcebus, Teilhardina and Omomys present shorter bodies relative to total astragalar length, whereas Marcgodinotius, Mirza, Smilodectes, Necrolemur, and most specimens of the genera Cantius, Notharctus and Eosimias present longer astragalar bodies relative to total astragalar length.

Regarding the width of the astragalar body relative to total astragalar length, $A$. frontanyensis exhibits a range that encompasses the values seen in Azibius, Asiadapis, most Microcebus and some specimens of Margodinotius, Mirza, Cantius and Eosimias, as well as one specimen of Omomys (UM 38321). Djebelemur, Cheirogaleus, Smilodectes, Teilhardina, Necrolemur, and most specimens of Omomys and Notharctus, as well as some specimens of Marcgodinotius, Microcebus, Mirza, Cantius and Eosimias present a slightly relatively wider body compared to $A$. frontanyensis. Smilodectes presents a much wider body than any of the 
other genera compared to total astragalar length. Only some Microcebus and some Cantius present relatively narrower bodies than $A$. frontanyensis.

When neck length is compared to total astragalar length, $A$. frontanyensis exhibits a range that encompasses the values of Mirza and some specimens of Cheirogaleus, Cantius, Notharctus, Smilodectes, Teilhardina and Omomys. Marcgodinotius, Asiadapis, Necrolemur and Eosimias have relatively short necks when compared with $A$. frontanyensis, whereas Azibius, Djebelemur, and all Microcebus except for one specimen (AMNH 174423) present relatively longer necks than $A$. frontanyensis. It should be noted that because of the medial angulation of the neck, the overall length of the astragalus does not include the whole length of the neck (see Fig. 3).

Omomys presents considerable variation in neck length; some specimens of this genus (e.g. UM 99806) present proportions that are within the range exhibited by $A$. frontanyensis, whereas some others have a shorter neck (e.g. UM 98908) or a longer neck (e.g. UM 32276). The neck angle of $A$. frontanyensis is within the range presented by Djebelemur and Azibius (specimen HGL50-466), and is less medially deviated than those of Asiadapis, Cantius, most Cheirogaleus, Eosimias, Marcgodinotius, Microcebus, Mirza, Necrolemur, most Notharctus, Omomys, Smilodectes, and Teilhardina.

The most proximal part of the astragalar body of $A$. frontanyensis differs from those of some Notharctus specimens (e.g. UCM 62671), as well as those of Necrolemur, some Omomys (e.g. UM 98908), and the extant strepsirrhines Cheirogaleus, Microcebus and Mirza (see Fig. 6, arrow 1 ) in being less laterally directed. Other specimens of Omomys differ in having the shelf margin directed towards the medial side (e.g. UM 98648). In addition, Cheirogaleus major (AMNH 100640) and Djebelemur present a "bulge" on the lateral side of the trochlear shelf that protrudes proximally (Fig. 6, arrow 2). This feature is lacking in A. frontanyensis, as well as the rest of the genera used for comparisons. The groove for the flexor fibularis tendon, on the proximoplantar end of the trochlear shelf, is laterally positioned in all observed strepsirrhines, whereas in haplorhines it is more centered with respect to the axis of the lateral tibial facet, with the exception of Teilhardina brandti, which appears to exhibit a more laterally positioned groove (Boyer and Seiffert, 2013), though more specimens of $T$. brandti are needed to assess the consistency of this trait.

Concerning the height of the astragalar body relative to trochlear width, $A$. frontanyensis falls within the range of values of Djebelemur, Smilodectes, Teilhardina and most Omomys, as well as some specimens of the genera Cheirogaleus, Microcebus, Mirza, Cantius, Notharctus 
and Eosimias. Azibius, Marcgodinotius, Asiadapis and Necrolemur always present higher astragalar bodies relative to trochlear width.

The trochlear rim orientation of $A$. frontanyensis is similar in Asiadapis, Azibius, Cantius, Cheirogaleus, Djebelemur, Eosimias, Marcgodinotius, Microcebus, Mirza, Necrolemur, and most Notharctus and Smilodectes. In these taxa, the medial rim is aligned with the trochlear groove, whereas the lateral rim diverges distolaterally. Some Cantius specimens present a very curved medial rim, not aligned with the trochlear groove (e.g. UCM 60918). In Omomys and Teilhardina, the lateral rim is the one aligned proximodistally with the trochlear groove, whereas the medial one diverges distomedially.

In A. frontanyensis, the lateral rim is slightly higher and sharper than the medial one. This is similar to the morphology of Asiadapis, Cantius, Djebelemur, Eosimias, Marcgodinotius, Microcebus, Mirza, Necrolemur, Notharctus, Smilodectes, and most Cheirogaleus. Teilhardina and some specimens of Omomys and Cheirogaleus (e.g., DPC 031) have a medial rim that is slightly higher than the lateral one, although the lateral one is still the sharpest. Specimens assigned to Omomys present a lot of variability, with some specimens presenting trochlear rims of similar height (like Teilhardina), while some others have either the lateral or the medial rim as the highest. The height and sharpness of the trochlear rims cannot be observed in Azibius due to abrasion.

The medial rim of the trochlea continues onto the neck in $A$. frontanyensis and ends with a transverse rim of bone on the proximal aspect of the neck (Fig. 4, arrow 1). This feature is also observed in Djebelemur and one specimen of Eosimias (IVVP V 11849). Although the medial trochlear rim also extends onto the neck in Cheirogaleus, Eosimias, Marcgodinotius (only in specimen GU748), Microcebus, and Mirza, these taxa differ in that the distal terminus of the medial rim projects strongly medially whereas it does not in $A$. frontanyensis and Djebelemur. The medial rim of the trochlea does not extend onto the neck in Asiadapis, Cantius, Notharctus, Smilodectes, and most Marcgodinotius. Azibius is too damaged to assess this feature. The medial rim of the trochlea does not continue onto the neck in Necrolemur, Omomys, or Teilhardina. These taxa with a restricted distal extent to the medial rim also tend to present squatting facets on the lateral side of the neck (Fig. 6, arrow 3), whereas this feature is not present in $A$. frontanyensis, other notharctines, asiadapines, djebelemurids, azibiids or extant strepsirrhines. Although notharctines are typically characterized as lacking squatting facets (Rose et al., 2009), one specimen of Notharctus (AMNH 12000) presents a feature that could be interpreted as such. 
The shallow trochlear groove of $A$. frontanyensis is similar to that of Asiadapis, Cantius, Cheirogaleus, Microcebus, Mirza, Smilodectes, Teilhardina, some Notharctus, and most Eosimias and Omomys. That of Djebelemur, even though the bone is slightly damaged, appears to be slightly shallower, as well as those of most Marcgodinotius; some Notharctus and Necrolemur have deeper trochlear grooves. This trait is not observable in Azibius.

There is no superior astragalar foramen, the lack of which is typical of euprimates, but possibly differentiates $A$. frontanyensis from some specimens of Marcgodinotius, Notharctus, and Smilodectes. Among other living and extinct primates, Adapis, Afradapis, Megaladapis, and lorises also have a superior astragalar foramen in at least some individuals (Dagosto, 1983; Godinot, 1991; Boyer et al., 2010).

The tubercle for the attachment of the talo-ectocuneiform ligament on the dorsolateral aspect of the neck is present in $A$. frontanyensis and many other genera, although this trait can sometimes be highly variable within a genus. The neck tubercle is clearly present in Asiadapis, Cheirogaleus, Djebelemur, Necrolemur, Smilodectes, some Cantius (e.g. USGS 6784), and most Notharctus. Those of some Asiadapis, Cantius, and Djebelemur are similar in shape to those of $A$. frontanyensis, although those of Asiadapis and Djebelemur are smaller. Those of Necrolemur, Smilodectes, and most Cheirogaleus and Notharctus present an elongated rim of bone that runs proximodistally on the dorsolateral side of the neck, which doesn't become a round tubercle as in $A$. frontanyensis, but that might have served the same purpose. On the other hand, there are specimens of Cantius (e.g. USGS 21832) and Notharctus (e.g.UCM 60918) that do not present a neck tubercle at all, and are like the specimens of Eosimias, Marcgodinotius, Teilhardina, and some Microcebus and Omomys (e.g. DPC 013294) in that respect. Moreover, some other genera present an enlargement of this area, but a discrete tubercle is not observable. This happens in Azibius, Mirza, some Notharctus (e.g. AMNH 131796) and Microcebus (e.g. AMNH 174472), and most Omomys.

In distal view, the astragalar head of $A$. frontanyensis is elliptical and widest mediolaterally. The mediolateral axis is also rotated slightly so that the medial side is elevated dorsally while the lateral side is depressed. In the terminology of other authors (Godinot and Dagosto, 1983), the oblique long axis is oriented dorsomedially, meaning that the highest part of the astragalar head is that on the medial side. The shape of the astragalar head can be represented by the index head length/head height (Fig. 5). The values of this ratio for $A$. frontanyensis overlap with Azibius, Eosimias, some Microcebus, some Notharctus, and one specimen of Omomys (UM 38321). The astragalar heads of Necrolemur and most Omomys specimens (e.g. UM 100600) are more rounded than those of $A$. frontanyensis. In contrast, the 
astragalar heads of Djebelemur, Marcgodinotius, Asiadapis, Cheirogaleus, Mirza, Cantius, Smilodectesand Teilhardina are more elliptical (shallower and wider) than those of $A$. frontanyensis.

Regarding the orientation of the astragalar head, that of $A$. frontanyensis is similar to those of Asiadapis, Azibius, Cantius, Cheirogaleus, Djebelemur, Marcgodinotius, Microcebus, Mirza, Necrolemur, Smilodectes, and most Notharctus in exhibiting medial inclination. Asiadapis and Mirza are at one end of the spectrum having the greatest medial inclination, while Azibius, Cantius, Cheirogaleus, Marcgodinotius, and Smilodectes tend to be intermediate in inclination and sometimes similar to $A$. frontanyensis. Djebelemur, Necrolemur, and most Notharctus have the least medial inclination; the sample of Notharctus presents substantial variability, however, in the inclination of the astragalar head, with some specimens even having an astragalar head that is inclined to the opposite side (dorsolaterally inclined, with the lateral part being higher, e.g. AMNH 131955). Moreover, Cheirogaleus, Notharctus, some Cantius, and one specimen of Marcgodinotius present more pronounced inclination than A. frontanyensis (e.g. USGS 21832, UCM 60920, GU 748, AMNH 80072). In addition, Microcebus is highly variable, with some astragalar heads sharing a similar angle with $A$. frontanyensis (e.g. AMNH 174383), and some others presenting more angled (e.g. AMNH 174423) or less angled (e.g. AMNH 174428) astragalar heads. In Eosimias and most Omomys the astragalar head is inclined to the opposite side, so that the lateral side is higher than in A. frontanyensis and other adapiforms (except for some Notharctus) and extant strepsirrhines observed. Teilhardina shows no dorsal inclination of the astragalar head [nor does one specimen of Omomys (UM 100600) and one specimen of Notharctus (UCM 70032)].

The navicular facet of $A$. frontanyensis also matches those of Djebelemur and Teilhardina in being of similar shape and in connecting with the neck tubercle (damage to the navicular facet of Azibius prevents comparison). In contrast, in Necrolemur and Smilodectes, as well as in the specimens of Cantius and Notharctus that present a neck tubercle, the navicular facet is not connected with the neck tubercle.

The sustentacular facet of $A$. frontanyensis presents a range of length and width that, when compared to trochlear width, overlaps with those of Djebelemur, Asiadapis and Teilhardina. The sustentacular facets of Azibius and Eosimias are also similar to that of $A$. frontanyensis in relative length, although the facet is wider in one specimen of Azibius (HGL50466), as well as in some Eosimias (e.g. IVPP V 12303). Most Omomys also fall within the range of $A$. frontanyensis for relative length of the sustentacular facet, but relative width of the facet is quite variable, with specimens that have narrower sustentacular facets than $A$. frontanyensis 
(e.g. UM 38321), others that fall within the range of the latter species (e.g. UM 98908), and some others that are wider (e.g. UM 98648). Moreover, the sustentacular facets of Omomys are generally placed more medially. Cantius and Necrolemur also present relative lengths of the sustentacular facet that overlap with $A$. frontanyensis, although Cantius has a relatively narrow facet, and Necrolemur a relatively wide one, when compared to the range of $A$. frontanyensis. On the other hand, the relative width of the sustentacular facet of Smilodectes overlaps with the range of $A$. frontanyensis, although its facet is comparatively relatively short. The sustentacular facets of Marcgodinotius, Microcebus and Mirza always present relatively long and wide sustentacular facets when compared to those of $A$. frontanyensis. Some Cheirogaleus present relative sustentacular length values that fall in the range of $A$. frontanyensis (e.g. DPC 1023), although some other have relatively long facets (e.g. DPC 0142); regarding relative width, Cheirogaleus always has wider sustentacular facets than $A$. frontanyensis. Most Notharctus overlap with the range of $A$. frontanyensis in relative sustentacular facet length, although they are generally relatively wider.The sustentacular and navicular facets of Cheirogaleus, Marcgodinotius, Microcebus, Mirza, Necrolemur, Notharctus, Omomys, and Smilodectes, are more confluent than those of $A$. frontanyensis (i.e., they are totally fused together), whereas in A. frontanyensis, specimens exhibiting the greatest confluence still present a lateral indentation where the facets join.

The fossa for the attachment of the posterior talotibial ligament (part of the deltoid ligament), located proximal to the medial tibial facet, is shallow in $A$. frontanyensis and matches the morphology seen in Cantius, Djebelemur, Mirza, Necrolemur, Smilodectes, and some Microcebus. A similarly developed fossa is present in most Marcgodinotius and Notharctus, and some Microcebus. It is less marked in other Asiadapis and Microcebus, and most Cheirogaleus. Again, Azibius is not well-preserved enough to assess this feature. The fossa present in Teilhardina is smaller than that of $A$. frontanyensis. Those of Eosimias and Omomys present substantial variability; the fossa of Omomys tends to be more rounded and marked than $A$. frontanyensis, while that of Eosimias tends to be less marked. However, both taxa also include individuals that are quite similar to $A$. frontanyensis.

Distal to this fossa is the medial tibial facet. The distal extension of the medial tibial facet is broken in one of the $A$. frontanyensis specimens (IPS-7712), but the preserved distal-most sliver of articular surface suggests that it was quite curved; the other complete astragalus (IPS7713) shows no curvature of the distal extension of the medial tibial facet. The medial tibial facets of the notharctines Cantius, Notharctus (most specimens), and Smilodectes, and those of the asiadapines Asiadapis and Marcgodinotius are more concave than those of $A$. frontanyensis 
and project more medially at their plantar margins (Fig. 6, arrow 4). In contrast, the medial tibial facets of Azibius, Djebelemur, Cheirogaleus, Microcebus, Mirza, and Necrolemur present no medial projection of the plantar side like that of $A$. frontanyensis. Omomys is variable, with some specimens presenting medial projection of the plantar side of the medial tibial facet (e.g. DPC 013285), whereas others resemble $A$. frontanyensis in having a more flat medial tibial facet (e.g. UCM 38321). In the case of Eosimias and Teilhardina, a medial projection of the plantar side of the medial tibial facet is present, but only on the distal part of the medial tibial facet. Though lacking concavity otherwise resulting from a medially projecting plantar margin, the tibial facet of A. frontanyensis does present a small, medially-projecting protuberance on the plantar margin (Fig. 4, arrow 2). This type of protuberance is also present in Asiadapis, Cheirogaleus, Eosimias, Marcgodinotius, Necrolemur, Omomys, and some individuals of Cantius (note that this observation is contra Gebo et al. [2001] who stated that this feature is never present in adapiforms and rare in omomyiforms). A similar kind of protuberance is also present in platyrrhines, cercopithecoids, hominoids and amphipithecids (Gebo et al., 1990; Marivaux et al., 2010).

The fossa for the attachment of the talofibular ligament on the proximal aspect of the lateral side of the astragalus exhibits relatively little interspecific variation in the comparative sample and many taxa are essentially similar to $A$. frontanyensis in this feature. However Asiadapis, Mirza, some Marcgodinotius, and most Cheirogaleus tend to have a shallower fossa; some Microcebus and most Omomys tend to have a relatively smaller one; Eosimias has a relatively larger one, and both Teilhardina and some Eosimias tend to present a deeper one. Moreover, Teilhardina, some Notharctus, and most Omomys tend to present a fossa that extends more plantarly.

The lateral astragalar process of $A$. frontanyensis is very similar to that of Mirza, most Microcebus and one specimen of Eosimias (IVPP V 11849) in size (i.e., when astragali are scaled to same body length) and shape. However, other Eosimias, Necrolemur, and Omomys present a smaller lateral astragalar process than that of $A$. frontanyensis. Asiadapis, Azibius, Djebelemur, Teilhardina, and some Cantius also present a lateral astragalar process of similar relative size to that of $A$. frontanyensis, but in these specimens the apex of the lateral astragalar process is less pointed and/or not directed distally. The lateral astragalar process of $A$. frontanyensis is more slender than those of Cheirogaleus, Marcgodinotius, Notharctus, and some Cantius. The size of the lateral astragalar process, which supports the fibular facet, is generally correlated with the slope of the facet. The fibular facet of $A$. frontanyensis forms an angle of around $108^{\circ}$ with the medial tibial facet, which is similar to the condition in Azibius, 
Cheirogaleus, Djebelemur, Marcgodinotius, Mirza, and Notharctus. Asiadapis, Cantius, Eosimias, Microcebus, Necrolemur, Omomys, and Teilhardina have a more acute angle (a steeper fibular facet).

The relative length of the ectal facet (compared to astragalar body length) of Cheirogaleus, as well as some specimens of Microcebus, Mirza, Teilhardina and Eosimias, falls within the range of $A$. frontanyensis. However, most of the specimens of Microcebus, Mirza and Teilhardina present relatively shorter ectal facets than $A$. frontanyensis, whereas those of some Eosimias are longer. The ectal facets of Azibius, Djebelemur, Marcgodinotius, Asiadapis, Cantius, Notharctus and Smilodectes are relatively short when compared to the range exhibited by $A$. frontanyensis. On the contrary, the ectal facets of Omomys and Necrolemur are relatively longer than those of $A$. frontanyensis. Regarding relative ectal facet width, the range of $A$. frontanyensis overlaps with Azibius, Cantius, Teilhardina and Eosimias, as well as some specimens of Marcgodinotius, Cheirogaleus, Microcebus, Mirza, Notharctus and one specimen of Smilodectes (AMNH 131774). Some specimens of Microcebus and Marcgodinotius present lower values than the range exhibited by $A$. frontanyensis, whereas Asiadapis, Omomys and Necrolemur present relatively wider ectal facets than $A$. frontanyensis; this is also true of most specimens of Cheirogaleus and Smilodectes, and some specimens of Mirza. The ectal facet of Cheirogaleus is generally less constricted in the middle, and those of Microcebus, Teilhardina and some Omomys (e.g. UM 100600) are more concave. Some Eosimias have ectal facets that are wide proximally, whereas a much wider proximal end is always present in Necrolemur. Both Smilodectes specimens available for comparison presented a damaged or incomplete ectal facet.

Comparisons with calcanei of other living and extinct primates

See Figure 7 for all genera used for comparisons, scaled to the same ectal facet and proximal calcaneal length. For a complete list of the specimens used for comparisons see SOM Table 1. See SOM Table 3 for mean calcaneal measurements of each genus used for comparisons as well as for $A$. frontanyensis. For box plots of astragalar indices for all the genera see Figure 8.

Regarding absolute size, primarily focusing on the combined lengths of the tuber and ectal facet, the calcaneus of $A$. frontanyensis is similar to those of Cheirogaleus medius, Marcgodinotius, Mirza and Necrolemur; smaller than those of Asiadapis, Cantius, Cheirogaleus 
major, Notharctus, Omomys, and Smilodectes; and larger than those of eosimiids, Microcebus and Teilhardina (Fig. 7).

Regarding morphology, the taxa whose calcanei show the most similarity to $A$. frontanyensis in terms of proportions are Mirza, Teilhardina, and most specimens of Omomys (though AMNH 29164 differs in exhibiting greater elongation); all of these taxa present similar elongation and width of both the proximal and distal parts of the calcaneus when standardized to the combined length of the calcaneal tuber and ectal facet. Some specimens of Cheirogaleus and Teilhardina (specimens AMNH 80072 and IRSNB-M1236) present a wider proximal half of the distal calcaneal segment, especially in the area closer to the ectal facet. Marcgodinotius, Asiadapis, Cheirogaleus, Cantius, Notharctus, Smilodectes, and eosimiids have substantially lower distal calcaneal elongation when compared with the range exhibited by $A$. frontanyensis (Fig. 8). The calcanei of Microcebus, Mirza and Necrolemur tend to present more distal calcaneal elongation than A. frontanyensis. Teilhardina and Omomys overlap with the range of A. frontanyensis when distal calcaneal elongation is compared to total calcaneal length. Moreover, Asiadapis (specimen GU 760), eosimiids, Notharctus, and some Cheirogaleus also have proportionally wider calcanei than those of $A$. frontanyensis

Standardized for size as described above, the relative ectal facet lengths of $A$. frontanyensis overlap with those of Marcgodinotius and Cheirogaleus. The rest of the taxa used for comparisons present relatively shorter ectal facets than $A$. frontanyensis. Regarding relative ectal facet width, $A$. frontanyensis overlaps with Marcgodinotius, Cheirogaleus and Omomys. Asiadapis, Necrolemur and Eosimias present relatively wider ectal facets than $A$. frontanyensis, whereas Microcebus, Mirza, Cantius, Smilodectes, Teilhardina and most Notharctus, present narrower ectal facets than $A$. frontanyensis. In addition, Omomys presents a more curved (more convex) ectal facet than $A$. frontanyensis.

A. frontanyensis does not appear to have a distinct distal sustentacular facet (Fig. 9), suggesting that the distal part of the astragalar neck was not in frequent contact with the calcaneal body in life. This condition also appears to be present in Teilhardina, as well as Microcebus and Mirza. Such individuals of Microcebus and Mirza present a sustentacular facet that extends farther distally than that of $A$. frontanyensis, which is rounded. In the case of Microcebus, the sustentacular facet area is also greater, which likely corresponds to its greater distal elongation. On the other hand, the sustentacular facet of Teilhardina is never larger than in $A$. frontanyensis. The rest of the specimens and taxa observed present distinct proximal and distal sustentacular facets observable as a constriction in the facet width somewhere along the facet's proximodistal length (forming an "8-shaped" facet), or by complete separation of the two 
facets by intervening non-articular area. In Marcgodinotius, Necrolemur, and Smilodectes, the proximal and distal sustentacular facets are connected so that they form an "8-shaped" facet (see example in Fig. 9E). This is also the condition in Asiadapis, Cantius, Omomys, and most Notharctus, although one specimen of Asiadapis (GU 707), two Cantius (Cantius frugivorus, USGS 6780 and Cantius abditus, USGS 21771), one Notharcus (AMNH 129382), and one specimen of Omomys (UCM 69303) present separate proximal and distal sustentacular facets (see example in Fig. 9D). Half of the Cheirogaleus specimens examined have connected and "8-shaped" proximal and distal sustentacular facets (e.g. DPC 0142), but the other half of the specimens present separate sustentacular facets (e.g. DPC 031). This latter condition is also found in two eosimiids (IVPP $\vee 11851$ and IVPP $\vee$ 12281), which have proximal and distal sustentacular facets that are not connected.

The position of the peroneal tubercle in A. frontanyensis is similar to those of Asiadapis, eosimiids, Mirza, Necrolemur, and those of most Cheirogaleus, Microcebus, and Omomys specimens, although those of Cheirogaleus, Microcebus, Mirza and Necrolemur are less developed. However, some Cheirogaleus specimens that appear to have a less developed peroneal tubercle present two prominences in this region: one that is located more proximodorsally and another one more distoplantarly (e.g. DPC 1023). The same is true for one specimen of Microcebus (AMNH 174430). Asiadapis presents variability in the development of the peroneal tubercle, as do eosimiids, although the latter usually present a larger peroneal tubercle than A. frontanyensis. Cantius, Marcgodinotius, Notharctus, Smilodectes, and Teilhardina usually present a more distally positioned peroneal tubercle than $A$. frontanyensis. The peroneal tubercle of Teilhardina is similar in size to that of $A$. frontanyensis, whereas those of Cantius and Notharctus usually have margins that rise more abruptly (rather than gradually) from the body of the calcaneus (Gladman et al., 2013); Smilodectes is variable in this feature.

When compared to the height of the bone at the ectal facet, the calcaneal body of $A$. frontanyensis is very low in proximal height, only comparable in this trait to one specimen of Cheirogaleus (DPC 0142). The rest of the genera used for comparisons present higher proximal parts of the calcaneus. The distal end of the calcaneus is also low in A. frontanyensis, and is only matched by one specimen of Cantius (USGS 21767). Concerning the height at the midpoint between the ectal and the sustentacular facets, $A$. frontanyensisis is similar to Cheirogaleus, Microcebus, Omomys and eosimiids. The rest of the taxa present a higher middle calcaneal region than $A$. frontanyensis. Necrolemur couldn't be measured due to the break that exists on the bone, which makes orientation difficult. 
The calcaneus of $A$. frontanyensis has a straight plantar edge, similar to those of most Mirza, Necrolemur, Notharctus, Omomys, Smilodectes, most Microcebus (some others are only slightly more curved), and some Cantius (some others are less straight due to a more plantar projection of the distal plantar tubercle). In contrast, those of Asiadapis, Marcgodinotius, Teilhardina, and most Cheirogaleus have a more concave plantar edge. Eosimiids exhibit substantial variability, with half of the specimens presenting a straight plantar aspect of the calcaneus, similar to that of $A$. frontanyensis, whereas some others present a more concave plantar edge.

The distal plantar tubercle of $A$. frontanyensis is similar to those of Mirza, Teilhardina, and most Cheirogaleus, Microcebus, and Omomys. Those of Asiadapis, Cantius, eosimiids, Marcgodinotius, Notharctus, and Smilodectes are always mediolaterally wider. In addition, Cantius presents different degrees of development of the distal plantar tubercle, whereas Asiadapis and some Microcebus sometimes present a more developed tubercle that extends farther plantarly. Moreover, in Smilodectes it is also generally less developed (less protruding plantarly), a condition that also occurs in Necrolemur.

The calcaneus of $A$. frontanyensis has a medially curved proximal part, with a proximal angle overlapping with Marcgodinotius, Cheirogaleus, and eosimiids. Teilhardina presents a smaller proximal angle than $A$. frontanyensis, whereas the rest of the taxa tend to present a larger proximal angle (that is less medial curvature), and thus are straighter in plantar view.

The cuboid facet of $A$. frontanyensis is very similar in shape to those of some Notharctus, most Omomys, and some Cantius and eosimiids. The cuboid facets of Cheirogaleus, Marcgodinotius, Mirza, Microcebus, Teilhardina, most Asiadapis and Notharctus, and some eosimiids and Omomys are more circular and less elliptical than that $A$. frontanyensis. Some specimens of Microcebus and Mirza also present a shallower pit than A. frontanyensis. Regarding size, the cuboid facet of $A$. frontanyensis (when calcanei are scaled to same tuber and ectal facet length) overlaps with the ranges presented by Mirza and Cantius. The rest of the taxa present larger cuboid facet areas than $A$. frontanyensis. Although the cuboid facet of Necrolemur couldn't be measured accurately because its cuboid facet is not well preserved, it seems to be smaller than that of $A$. frontanyensis.

The proximal aspect of the tuber calcanei of $A$. frontanyensis resembles that of Teilhardina. However, Cheirogaleus, Marcgodinotius, Notharctus, most Cantius, and some Asiadapis, eosimiids, and Mirza present a larger proximal aspect of the tuber calcanei than $A$. frontanyensis, whereas Smilodectes, most Cheirogaleus, and some Asiadapis and Cantius exhibit a relatively wider tuber. Moreover, Omomys generally presents a larger proximal part of 
the calcaneus that is usually wider dorsally than that of $A$. frontanyensis. In Necrolemur the tuber is larger and deeper dorsoplantarly. In addition, some genera such as Cheirogaleus, Microcebus, Mirza, Necrolemur and Omomys present a distal protrusion of the dorsomedial side of the proximal end of the tuber calcanei that is not present in A. frontanyensis (Fig. 7, arrows).

Phylogenetic position of Anchomomys frontanyensis

All of the phylogenetic analyses agree in placing Anchomomys and other European anchomomyins closer to crown Strepsirrhini than to any other European, Asian, or North American adapiforms (Fig. 10). Notharctidae and its alleged subfamily Cercamoniinae (sensu Godinot, 1998), which is often defined as including Anchomomyini, are polyphyletic in all analyses. Despite the consistent placement of European anchomomyins as close relatives of both crown strepsirrhines and the African stem strepsirrhine families Azibiidae, Djebelemuridae, and Plesiopithecidae, their position relative to those taxa varies considerably across the three different analyses. When re-evolution of premolars is not allowed, parsimony analysis places three of four included anchomomyins as a sister clade of crown strepsirrhines, azibiids, djebelemurids, and plesiopithecids, but with Anchomomys gaillardi separated from other European taxa and nested among djebelemurids, which emerge as paraphyletic with respect to Azibiidae (Fig. 10A). Interestingly, parsimony analysis of the same data set with no postcranial characters scored for Anchomomys recovers a European anchomomyin clade that includes $A$. gaillardi (SOM Fig. 2). When premolars are allowed to re-evolve, all of the European anchomomyins form a clade whose consecutive sister taxa are Azibiidae, Djebelemuridae, and a Karanisia-Plesiopithecus clade, all of which are African and would therefore imply an African origin for Anchomomyini (Fig. 10B). Importantly, this tree also implies re-evolution of $\mathrm{P}^{1} / 1$ and reenlargement of $\mathrm{P}^{2} / 2$ in adapines, which are nested within Caenopithecinae, with late Eocene African Aframonius as their closest relative. The Bayesian analysis of the same data set agrees more closely with the parsimony analysis that was constrained to disallow premolar re-evolution, requiring no such reversals and placing a well-supported anchomomyin clade in an unresolved position with respect to Azibiidae, Djebelemuridae, and crown Strepsirrhini (Fig. 10C). Outside of stem and crown Strepsirrhini, the major difference between the two phylogenetic methods used here is that omomyiforms are either paraphyletic with respect to tarsiers (both parsimony analyses) or paraphyletic with respect to tarsiers and anthropoids (Bayesian analysis).

Ten unambiguous synapomorphies support the placement of anchomomyins as the sister group of a djebelemurid-azibiid-crown strepsirrhine clade on the strict consensus tree 
recovered by parsimony analysis with premolar loss treated as irreversible (SOM Table 4). Only one of these unambiguous synapomorphies (calcaneal width/length changing from being variable $(>35<40$ or $>40<45$ ) to being fixed as $>35<40$ ) is from the postcranium.

\section{Discussion}

Attribution of the fossil elements

The attribution of elements described here to Anchomomys from the locality of Sant Jaume de Frontanyà-3C (SJF-3C) can be questioned on two related and one independent criteria: 1) Are they diagnostically primate? 2) Are they diagnostically similar to extant strepsirrhines? 3) Are they of the expected absolute size for Anchomomys? We make a strong case that they are diagnostically strepsirrhine, which ipso facto demonstrates that they are also primate. This is most easily documented for the astragalus. The strepsirrhine affinities of the astragali described here are supported by their laterally positioned grooves for the tendon of flexor fibularis (e.g., Beard et al., 1988; Williams et al., 2010), large posterior trochlear shelf (e.g., Gebo, 1988; Williams et al., 2010), and laterally sloping fibular facet (e.g., Gebo, 1988; Boyer and Seiffert, 2013). The lateral tibial facet forms an angle of $108.5^{\circ}$ with the fibular facet (following the measurement method of Boyer and Seiffert, 2013: Table 1). These observations are strong strikes against the alternative hypothesis that this element belongs to the haplorhine microchoerine Pseudoloris pyrenaicus (Minwer-Barakat et al., 2010; this study). The morphology of the calcaneus is more taxonomically ambiguous. However, the pronounced distal elongation is certainly diagnostic for "prosimian" primates.

To further refine the attribution, we considered the absolute size of the bones. Considering absolute size allows the astragali and calcanei described here to be confidently attributed to $A$. frontanyensis to the exclusion of other primate taxa from the same level because (1) they fit the expected $\mathrm{m} / 2$ lengths for this taxon (Fig. 1) and (2) both of the other primates from the same stratigraphic levels (Pseudoloris pyrenaicus and Adapis sp.), have $\mathrm{m} / 2$ sizes that fall outside of the $95 \%$ prediction intervals for both astragalar trochlear width and calcaneocuboid facet area (length $\mathrm{x}$ width). The omomyiform $P$. pyrenaicus has tooth dimensions that fall below the confidence limit of the equation, while Adapis sp. has dimensions well above the limit predicted by the postcrania described here. Moreover, we note the existence of astragalar remains attributable to a small omomyiform that are under study and have been recovered from the same levels. These astragalar remains are much smaller than 
those attributed to $A$. frontanyensis and do not match the ectal facet sizes of the calcanei described here. We are thus very confident that we have correctly attributed these tarsals to Anchomomys.

Functional and adaptive significance of morphology

After extensive comparisons among fossil prosimians and extant strepsirrhines, it can be said that the astragalus of $A$. frontanyensis most resembles that of Djebelemur, and to a lesser extent those of Azibius or Mirza. Regarding the calcaneus, that of $A$. frontanyensis differs from known adapiforms, and more closely resembles those of the cheirogaleid Mirza or the omomyiform Teilhardina, especially taking into account its gracility and distal elongation. Calcaneal comparisons with Azibius and Djebelemur are unfortunately not yet possible as these elements are currently unknown.

The astragalus and calcaneus of $A$. frontanyensis present some features that appear to be related to a proclivity for climbing rather than leaping, such as a dorsally tall and proximodistally elongate ectal facet of the calcaneus (Gebo, 1988). However, it also presents features related to leaping, such as a long and straight astragalar neck (deflected less than $20^{\circ}$ medially), a moderately tall astragalar body, almost parallel trochlear rims, slight trochlear grooving, a straight plantar edge of the calcaneus, and elongation of the distal part of the calcaneus (Gebo, 1988; Boyer et al. 2013a).

Though calcaneal elongation is frequently associated with leaping specialization (Napier and Walker, 1967; Gebo 1988), it is well-known that this relationship is affected by allometric effects (Boyer et al. 2013a). Thus the presence of much greater elongation in $A$. frontanyensis compared to most other "notharctids" (Fig. 8) does not necessarily indicate that it was more specialized for strong leaping; high distal calcaneal elongation in A. frontanyensis compared to "notharctids" may be explained partly by its smaller body size as suggested by Moyà-Solà et al. (2011) and Boyer et al. (2013a). However, when distal calcaneal elongation is plotted against body mass (Boyer et al., 2013a), $A$. frontanyensis clearly presents more elongation for its mass than other "notharctids," and even more than some omomyiforms. We interpret this to indicate that $A$. frontanyensis was in fact more leaping reliant than were other "notharctids." By the same logic, it is even possible that it was a more capable leaper than certain omomyiforms such as Teilhardina and Tetonius (Boyer et al., 2013a). Consistent with these interpretations are the conclusions of Roig and Moyà-Solà (2010), who argued that an undescribed first metatarsal of A. frontanyensis possessed a well-developed peroneal process like those of extant 
strepsirrhines, which has been related to a high degree of hallucal abduction and grasp-leaping behaviour (Jacobs et al., 2009; Goodenberger et al. 2015). On the other hand, A. frontanyensis also presents features that allow greater foot mobility and that are lacking even in early omomyiforms as mentioned above. These include a more curved and proximodistally oriented ectal facet on the calcaneus, a broad and oval astragalar head, and an oval proximal navicular facet (Gebo, 1988). Moreover, omomyiforms are known to have more elongate cuneiforms, naviculars and cuboids than adapiforms, and these features, together with the calcaneus, have also been used to infer leaping specialization (Gebo, 1988; Rose, 1994; Anemone and Covert, 2000; Dunn et al., 2006; Dunn, 2010). Thus, it is possible that small anchomomyins only matched omomyiforms in calcaneal elongation but not in the elongation of other tarsals, despite their similar body sizes. If so, this could alter the view of whether Anchomomys was as proficient a leaper as early omomyiforms. Another key variable in assessment of leaping specialization in small bodied taxa is intermembral index. The close relative of Teilhardina, Archicebus achilles, has a value of $<60$, suggesting strong leaping specialization. This hypothesis generated by calcaneal differences predicts a low intermembral index in Anchomomys. In light of missing data and the mosaic of leaping traits in A. frontanyensis and early omomyiforms, it is probably premature to draw conclusions about which was more leaping proficient; more evidence from the postcranial skeleton is needed to test these interpretations and refine locomotor hypotheses.

A more direct comparison can be made with the older adapiform Marcgodinotius, which is of similar size, but shows much less calcaneal elongation (Fig. 8). Thus the differences in elongation between $A$. frontanyensis and Marcgodinotius cannot be explained by size alone. These differences are most parsimoniously interpreted as the result of differences in leaping performance, which probably correlates with degree of leaping reliance (though not necessarily). If Marcgodinotius retains a calcaneal morphology that is more similar to that of the ancestral euprimate than is that of $A$. frontanyensis (as suggested by analyses of Boyer et al. 2013a), then this indicates that the ability to leap effectively improved fitness in at least some anchomomyins. Because early omomyiforms have similar degrees of elongation to $A$. frontanyensis, but more derived omomyiforms have greater elongation, this suggests that increases in calcaneal elongation evolved multiple times in early primate evolution, just as it must have evolved separately in galagos and tarsiers. As Boyer et al. (2013a) noted, the frequent evolution of increased calcaneal elongation would suggest an early primate niche space that frequently exposed species to selection pressures that favored more efficient leaping. 
Anchomomys frontanyensis and Marcgodinotius also differ in functionally important aspects of astragalar morphology: we can clearly see that Marcgodinotius exhibits fewer features expected for a specialized leaper. These include a shorter and more angled astragalar neck and a shallower trochlear groove (Gebo, 1988). In addition, the astragalar head of Marcgodinotius is wider mediolaterally and shallower dorsoplantarly than that of $A$. frontanyensis, a condition reminiscient of lorises and associated with more climbing capabilities (Gebo, 1988). Though A. frontanyensis is not as different from Marcgodinotius as would be expected for a strictly specialized leaper -especially considering the "wedge" shape of its trochlea (Gebo, 1988) - it clearly was a more leaping reliant animal.

To sum up, the astragalus and calcaneus of $A$. frontanyensis indicate a generalized locomotor behaviour, but with more proclivity for leaping than any other adapiform known from these bones (including adapines, Marcgodinotius, Asiadapis, Cantius, Notharctus and Smilodectes). Though it was previously analogized with Cheirogaleus (Roig and Moyà-Solà, 2011), Mirza is probably a more appropriate analogue among cheirogaleids, as that genus exhibits slightly greater agility and greater tendencies for leaping (Gebo, 1985). We hope to have the opportunity to test these conclusions from the tarsals in the future with more complete skeletal remains. Intermembral indices should be quite definitive relative to tarsal morphology, as the morphological response of the ankle to permanent modal changes in a species' behaviour is probably relatively slow (Boyer et al. 2013a).

Phylogenetic significance of Anchomomys' tarsal morphology

The phylogenetic analysis presented in Marigó et al. (2011), within which A. frontanyensis was scored solely for dental characters, opened two alternative hypotheses for the phylogenetic relationships of anchomomyins. The first hypothesis suggested that anchomomyins were more closely related to crown strepsirrhines than to adapiforms, while the second one suggested instead that they were more closely related to asiadapine adapiforms. We have now been able to re-examine these competing hypotheses with additional information from the astragalus and calcaneus, as well as some data from the navicular (Roig and MoyàSolà, 2010, 2011; Marigó et al., 2014), the latter of which has not yet been formally described.

The three new analyses presented here show three slightly different placements of anchomomyins, none of which indicates a close relationship of $A$. frontanyensis and asiadapines. Incongruent positions for $A$. gaillardi in particular, and for the rest of the anchomomyins in general, as well as low $(<50)$ bootstrap support for all nodes rootward of 
anchomomyins, indicate that there is still substantial instability in basal strepsirrhine phylogeny, and that definitive statements about the phylogenetic position of anchomomyins require further evidence. On the other hand, it is reassuring that the three trees recovered from the different phylogenetic analyses performed (Fig. 10) all recover a position for anchomomyins that is closer to African djebelemurids, azibiids, and crown strepsirrhines than to other adapiforms. Only one of the unambiguous synapomorphies supporting the placement of anchomomyins with azibiids, djebelemurids, and crown strepsirrhines is from the tarsus (decrease in the calcaneal width/length ratio, see SOM Table 4); the rest are dental and mandibular features.

To sum up, the addition of $A$. frontanyensis postcranial material to phylogenetic analyses of living and extinct primates provides no support for a relationship with asiadapines or "cercamoniines", and consistently suggests that this anchomomyin is closely related to djebelemurids, azibiids, and crown strepsirrhines. This result is strongly supported by our Bayesian phylogenetic analysis (posterior probability for that clade $=0.98$ ), but not by parsimony bootstrap. In light of this, these results need to be taken with caution; although strong similarities exist among the astragali of $A$. frontanyensis, djebelemurids, and azibiids, there are also several differences such as the large canine and lack of crowding in the postcanine teeth of A. frontanyensis (Marigó et al., 2011), the lack of which have been interpreted as synapomorphies supporting a relationship of the African Eocene forms and extant strepsirrhines. While lack of such synapomorphies runs counter to a monophyletic relationship between Djebelemur and anchomomyins to the exclusion of extant strepsirrhines, these taxa may still be closely related; some dental characters that have been noted to suggest a closer relationship between djebelemurids and crown strepsirrhines (see Marivaux et al., 2013) are also present in anchomomyins such as the single rooted $\mathrm{P}_{2}$, long and simple premolars with a blade-like protoconid and some premolar crowding (see Mazateronodon endemicus, $A$. frontanyensis and Nievesia sossisensis in Marigó et al., 2010, 2011, 2013). In addition, a premetacristid that joins the paracristid in the lower molars and that completely closes the trigonid basin is a feature that was claimed to be a synapomorphy of Djebelemur and extant strepsirrhines (Marivaux et al., 2013), although it is clearly present in some anchomomyins (see Marigó et al., 2010, 2013). Other traits that group them together, such as small size, occur in primitive adapiforms such as Donrussellia; as such we are not confident that the small size of these "advanced" (or more crown-ward) stem strepsirrhines is not simply due to retention of the primitive condition within Strepsirrhini.

\section{Summary and Conclusions}


The astragalus and calcaneus of Anchomomys frontanyensis are described in detail. The morphology of the astragalus closely resembles that of the early Eocene African fossil Djebelemur martinezi.

The calcaneus of Djebelemur is not yet known and thus comparisons are not possible, but the calcaneus of $A$. frontanyensis closely resembles those of the extant cheirogaleid Mirza or the early omomyiform Teilhardina in overall proportions, while exhibiting a proportionally longer ectal facet and a more proximally placed peroneal tubercle than Teilhardina.

The calcaneal and astragalar morphology of Anchomomys frontanyensis allows us to reconstruct it as an arboreal quadruped with notable specializations for leaping. A good extant analogue for this fossil species, in terms of locomotor adaptations, may be the extant strepsirrhine genus Mirza. Even though A. frontanyensis is not reconstructed as a highly specialized leaper, it presents more calcaneal elongation than other adapiforms and early omomyiforms when body mass is taken into account, which may represent an increased specialization for leaping in this taxon when compared to other Eocene primates. If asiadapines represent the primitive condition for adapiforms and early omomyiforms do not present extreme leaping specialization, this would suggest that adapiforms and omomyiforms increased their leaping specialization in parallel, and may reflect similar modal environmental selective pressures on different early euprimate lineages.

The topologies recovered by our phylogenetic analyses suggest, despite their instability, a closer relationship between anchomomyins, djebelemurids and azibiids than between anchomomyins and other adapiforms. If additional data come to indicate that anchomomyins, djebelemurids and azibiids are not closely related, and that the trees recovered are artifacts of convergences existing between them, this could indicate that lemuriform-like dental and postcranial synapomorphies evolved convergently. Just as the pressure for better leaping seems to have affected more than one euprimate lineage, perhaps pressures for a more strepsirrhine-like dentition did as well. In order to test these competing hypotheses, more fossil material is needed to reveal other aspects of the anchomomyin skeleton.

\section{Acknowledgements}

This study has been financed by the National Science Foundation (NSF BCS 1317525 to D.M. Boyer \& E.R. Seiffert), the Spanish Ministerio de Economía y Competitividad (CGL201454373-P) and the Generalitat de Catalunya (2014 SGR 416 GRC and 2014/100604). J. Marigó 
has also been funded by the Fondation Fyssen. We thank the following people/institutions: P.D. Gingerich (for Access to UM notharctine and omomyine material); L. Marivaux (for scans of Djebelemur and Necrolemur); K.C. Beard (for access to IVPP eosimiid material), T. Smith (for access to IRSNB Teilhardina material) Pat Holroyd (UCMP omomyiform material), B. Covert (UCM omomyiform material), Gregg Gunnell (for access to DFP holdings); K.D. Rose (GU asiadapid material and USGS notharctine material).

We thank James Thostenson and the Duke University Shared Materials Instrumentation Facility (SMIF) for access to the microCT scanner.

We also thank Mark Teaford and two anonymous reviewers whose comments greatly improved the manuscript.

\section{References}

3D Systems Inc., 2013. Geomagic Studio. In. Rock Hill: 3D Systems Inc.

Anemone, R.L., Covert, H.H., 2000. New skeletal remains of Omomys (Primates, Omomyidae): functional morphology of the hindlimb and locomotor behavior of a Middle Eocene primate. J. Hum. Evol. 38, 607-633.

Bacon, A.-M., Godinot, M., 1998. Analyse morphofonctionnelle des femurs et des tibias des "Adapis" du Quercy: mise en evidence de cinq types morphologiques. Folia Primatol. 69, 1-21.

Beard, K.C., Dagosto, M., Gebo, D.L., Godinot, M., 1988. Interrelationships among primate higher taxa. Nature 331, 712-714.

Bloch, J.I., Silcox, M.T., Boyer, D.M., Sargis, E.J., 2007. New Paleocene skeletons and the relationship of plesiadapiforms to crown-clade primates. Proc. Natl. Acad. Sci. 104(4), 1159-1164.

Boyer, D.M., Seiffert, E.R., 2013. Patterns of astragalar fibular facet orientation in extant and fossil primates and their evolutionary implications. Am. J. Phys. Anthropol. 151, 420-447.

Boyer, D.M., Patel, B.A., Larson, S.G., Stern, J.T., 2007. Telemetered electromyography of peroneus longus in Varecia variegata and Eulemur rubriventer: implications for the functional significance of a large peroneal process. J. Hum. Evol. 53, 119-134.

Boyer, D.M., Seiffert, E.R., Simons, E.L., 2010. Astragalar morphology of Afradapis, a large adapiform primate from the earliest Late Eocene of Egypt. Am. J. Phys. Anthropol. 143, 383-402. 
Boyer, D.M., Seiffert, E.R., Gladman, J.T., Bloch, J.I., 2013a. Evolution and allometry of calcaneal elongation in living and extinct primates. PLoS ONE 8(7), e67792.

Boyer, D.M., Yapuncich, G.S., Chester, S.G.B., Bloch, J.I., Godinot, M., 2013b. Hands of early primates. Am. J. Phys. Anthropol. 57, 33-78.

Cartmill, M., 1972. Arboreal adaptations and the origin of the order Primates. In: Tuttle, R.H. (Ed.), The Functional and Evolutionary Biology of Primates. Aldine Press, Chicago, pp. 97-122

Cartmill, M., 1974a. Rethinking primate origins. Science 184, 436-443.

Cartmill, M., 1974b. Pads and claws in arboreal locomotion. In: Jenkins, F.A., Jr. (Ed.), Primate Locomotion. Academic Press, New York, pp. 45-83.

Cartmill, M., 1992. New views on primate origins. Evol. Anthropol. 1, 105-111.

Dagosto, M., 1983. Postcranium of Adapis parisiensis and Leptadapis magnus (Adapiformes, Primates). Folia Primatol. 41, 49-101.

Dunn, R.H., 2010. Additional postcranial remains of omomyid primates from the Uinta Formation, Utah and implications for the locomotor behavior of large-bodied omomyids. J. Hum. Evol. 58, 406-417

Dunn, R.H., Sybalsky, J.M., Conroy, G.C., Rasmussen, D.T. (2006). Hindlimb adaptations in Ourayia and Chipetaia, relatively large-bodied omomyine primates from the Middle Eocene of Utah. Am. J. Phys. Anthropol. 131, 303-310.

Franzen, J.L., 1987. Ein neuer Primate aus dem Mitteleozän der Grube Messel (Deutschland, S-Hessen). Cour. Forsch.-Institut Senckenberg 91, 151-187.

Franzen, J.L., 2000. Der sechste Messel-Primate (Mammalia, Primates, Notharctidae, Cercamoniinae). Senckenbergiana lethaea 80(1), 289-303.

Franzen, J.L., Gingerich, P.D., Habersetzer, J., Hurum, J.H., von Koenigswald, W., Smith, B.H., 2009. Complete primate skeleton from the Middle Eocene of Messel in Germany: Morphology and paleobiology. PLos ONE 4(5), e5723.

Gebo, D.L., 1985. The nature of the primate grasping foot. Am. J. Phys. Anthropol. 67, 269-288.

Gebo, D.L., 1988. Foot morphology and locomotor adaptation in Eocene primates. Folia Primatol. 50, 3-41.

Gebo, D.L., 1989. Locomotor and phylogenetic considerations in anthropoid evolution. J. Hum. Evol. 18, 201-203.

Gebo, D.L., Dagosto, M., Rosenberger, A.L., Setogushi, T., 1990. New platyrrhine tali from La Venta, Colombia. J. Hum. Evol 19, 737-746. 
Gebo, D.L., Dagosto, M., Rose, K.D., 1991. Foot morphology and evolution in Early Eocene Cantius. Am. J. Phys. Anthropol. 86, 51-73.

Gebo, D.L., Dagosto, M., Beard, K.C., Qi, T., 2001. Middle Eocene primate tarsals from China: Implications for haplorhine evolution. Am. J. Phys. Anthropol. 116, 83-107.

Gheerbrant, E., Thomas, H., Roger, J., Sen, S., Al-Sulaimani, Z., 1993. Deux nouveaux primates dans l'Oligocene Inferieur de Taqah (Sultanat d'Oman): Premiers Adapiformes (?Anchomomyini) de la Peninsule Arabique? Palaeo Vertebrata 22(4), 142-196.

Gilbert, C.C., Rossie, J.B., 2007. Congruence of molecules and morphology using a narrow allometric approach. Proc. Natl. Acad. Sci. 104(29), 11910-11914.

Gingerich, P.D., 1977. New species of Eocene primates and the phylogeny of European Adapidae. Folia Primatol. 28, 60-80.

Gladman, J.T., Boyer, D.M., Simons, E.L., Seiffert, E.R., 2013. A calcaneus attributable to the primitive Late Eocene anthropoid Proteopithecus sylviae: Phenetic affinities and phylogenetic implications. Am. J. Phys. Anthropol. 151,372-397.

Godinot, M., 1988. Les primates adapidés de Bouxwiller (Eocène Moyen, Alsace) et leur apport à la compréhension de la faune de Messel et à l'évolution des Anchomomyini. Cour. Forsch.-Institut Senckenberg 107, 383-407.

Godinot, M., 1989. Postcranial anatomy and locomotor behavior of two contemporaneous species of Adapis (Eocene, Adapiformes). Am. J. Phys. Anthropol. 78, 228-229.

Godinot, M., 1991. Toward the locomotion of two contemporaneous Adapis species. Z. Morph. Anthropol. 78, 387-405.

Godinot, M., 1992. Early euprimate hands in evolutionary perspective. J. Hum. Evol. 22(4-5), 267-283.

Godinot, M., 1998. A summary of adapiform systematics and phylogeny. Folia Primatol. 69, 218-249.

Godinot, M., Beard, K.C., 1991. Fossil primate hands: a review and an evolutionary inquiry emphasizing early forms. Hum. Evol. 6, 307-354.

Godinot, M., Dagosto, M., 1983. The astragalus of Necrolemur (Primates, Microchoerinae). J. Paleontol. 57(6), 1321-1324.

Godinot, M., Jouffroy, F.K., 1984. La main d'Adapis. In: Buffetaut, E., Mazin, J.-M., Salmon, E., (Eds.). Actes du Symposium Paleontologique G. Cuvier. Montbeliard, Le Serpentaire, pp. 221-241.

Gregory, W.K., 1920. On the structure and relations of Notharctus, an American Eocene primate. Mem. Amer. Mus. Nat. Hist III, 49-243. 
Jacobs, R.L., Boyer, D.M., Patel, B.A., 2009. Comparative functional morphology of the primate peroneal process. J. Hum. Evol. 57, 721-731.

Marigó, J., Minwer-Barakat, R., Moyà-Solà, S., 2010. New Anchomomyini (Adapoidea, Primates) from the Mazaterón Middle Eocene locality (Almazán Basin, Soria, Spain). J. Hum. Evol. 58, 353-361.

Marigó, J., Minwer-Barakat, R., Moyà-Solà, S., 2011. New Anchomomys (Adapoidea, Primates) from the Robiacian (Middle Eocene) of northeastern Spain. Taxonomic and evolutionary implications. J. Hum. Evol. 60, 665-672.

Marigó, J., Minwer-Barakat, R., Moyà-Solà, S., 2013. Nievesia sossisensis, a new anchomomyin (Adapiformes, Primates) from the early Late Eocene of the southern Pyrenees (Catalonia, Spain). J. Hum. Evol. 64, 473-485.

Marigó, J., Boyer, D.M., Minwer-Barakat, R., Moyà-Solà, S., 2014. Navicular remains of Anchomomys frontanyensis (Adapoidea, Primates) from the Middle Eocene of Sant Jaume de Frontanyà (Northeastern Spain). Am. J. Phys. Anthropol. 153(S58), 176-177.

Marivaux, L., Chaimanee, Y., Ducrocq, S., Marandat, B., Sudre, J., Soe, A.N., Tun, S.T., Htoon, W., Jaeger, J.-J., 2003. The anthropoid status of a primate from the late middle Eocene Pondaung Formation (Central Myanmar): Tarsal evidence. Proc. Natl. Acad. Sci. 100(23), 13173-13178.

Marivaux, L., Beard, K.C., Chaimanee, Y., Dagosto, M., Gebo, D.L., Guy, F., Marandat, B., Khaing, K., Kyaw, A.A., Oo, M., Sein, C., Soe, A.N., Swe, M., Jaeger, J.J., 2010. Talar morphology, phylogenetic affinities, and locomotor adaptation of a large-bodied amphipithecid primate from the late middle Eocene of Myanmar. Am. J. Phys. Anthropol. 143, 208-222.

Marivaux, L., Tabuce, R., Lebrun, R., Ravel, A., Adaci, M., Mahboubi, M., Bensalah, M., 2011. Talar morphology of azibiids, strepsirhine-related primates from the Eocene of Algeria: Phylogenetic affinities and locomotor adaptation. J. Hum. Evol. 61, 447-457.

Marivaux, L., Ramdarshan, A., Essid, E.M., Marzougui, W., Ammar, H.K., Lebrun, R., Marandat, B., Merzeraud, G., Tabuce, R., Vianey-Liaud, M., 2013. Dejebelemur, a tiny pre-toothcombed primate from the Eocene of Tunisia: A glimpse into the origin of crown strepsirhines. PLoS ONE 8(12), e80778.

Miller, M.A., Pfeiffer, W., and Schwartz, T. 2010. Creating the CIPRES Science Gateway for inference of large phylogenetic trees. In: Proceedings of the Gateway Computing Environments Workshop (GCE), 14 Nov. 2010, New Orleans, LA pp 1 - 8. 
Minwer-Barakat, R., Marigó, J., Moyà-Solà, S., 2010. A New species of Pseudoloris (Omomyidae, Primates) from the Middle Eocene of Sant Jaume de Frontanyà (Eastern Pyrenees, Spain). Am. J. Phys. Anthropol. 143, 92-99.

Moyà-Solà, S., Köhler, M., 1993. Middle Bartonian locality with Anchomomys (Adapidae, Primates) in the Spanish Pyrenees: Preliminary report. Folia Primatol. 60, 158-163.

Moyà-Solà, S., Köhler, M., Alba, D.M., Roig, I., 2011. Calcaneal proportions in primates and locomotor inferences in Anchomomys and other Paleogene Euprimates. Swiss J. Palaeontol. 130(2), 187-324.

Napier, J.R., Walker, A.C., 1967. Vertical clinging and leaping - a newly recognized category of locomotor behaviour of primates. Folia Primatol. 6, 204-219.

Rasmussen, D.T., Nekaris, K.A. 1998. Evolutionary history of lorisiform primates. Folia Primatol. 69(1), 250-285.

Ravosa, M.J., Dagosto, M. (Eds.), 2007. Primate Origins: Adaptations and Evolution. Springer, Chicago.

Ronquist, F., Teslenko, M., van der Mark, P., Ayres, D.L., Darling, A., Höhna, S., Larget, B., Liu, L., Suchard, M.A., Huelsenbeck, J.P., 2012. MrBayes 3.2: Efficient Bayesian phylogenetic inference and model choice across a large model space. Syst. Biol. 61, 539-542.

Roig, I., Moyà-Solà, S., 2010. Functional morphology of the peroneal process of Anchomomys (Adapoidea) from the Middle Eocene of Sant Jaume de Frontanyà (Catalonia, Spain). Primate Research 26 (Suppl.), 452.

Roig, I., Moyà-Solà, S., 2011. The postcranial morphology of Anchomomys frontanyensis and its implications for understanding the locomotion of the earliest primates. Suppl. to the online J. Vert. Paleont. 180-181.

Roig, I., Moyà-Solà, S., Köhler, M., Alba, D.M., Minwer-Barakat, R., Marigó, J., 2009. Locomotor inferences in Anchomomys Stehlin, 1916 (Primates, Adapidae) on the basis of calcaneal proportions. Paleolusitana 1, 419-423.

Rose, K.D., 1994. The earliest primates. Evol. Anthropol. 3: 159-173.

Rose, K.D., Rana, R.S., Sahni, A., Kumar, K., Missiaen, P., Singh, L., Smith, T., 2009. Early Eocene primates from Gujarat, India. J. Hum. Evol. 56, 366-404.

Sargis, E.J., Boyer, D.M., Bloch, J.I., Silcox, M.T., 2007. Evolution of pedal grasping in Primates. J. Hum. Evol. 53, 103-107.

Schmid, P., 1979. Evidence for microchoerine evolution from Dielsdorf (Zürich Region, Switzerland) - a preliminary report. Folia Primatol. 31, 301-311. 
Seiffert, E.R., Simons, E.L., 2001. Astragalar morphology of late Eocene anthropoids from the Fayum Depression (Egypt) and the origin of catarrhine primates. J. Hum. Evol. 41, 577606.

Seiffert, E.R., Perry, J.M.G., Simons, E.L., Boyer, D.M., 2009. Convergent evolution of anthropoid-like adaptations in Eocene adapiform primates. Nature 461, 1118-1122.

Simons, E.L., 1962. A new Eocene primate genus, Cantius, and a revision of some allied European lemuroids. Bull. British Mus. (Nat. Hist.) 7(1), 1-36.

Stehlin, H.G., 1916. Die Säugetiere des schweizerischen Eocaens. Abh. Schweiz. Paläont. Ges. 41(7), 1299-1552.

Strait, D.S., Grine, F.E., 2004. Inferring hominoid and early hominid phylogeny using craniodental characters: The role of fossil taxa. J. Hum. Evol. 47, 399-452.

Sussman, R.W., Raven, P.H., 1978. Pollination by lemurs and marsupials: An archaic coevolutionary system. Science $200,731-736$.

Tabuce, R., Marivaux, L., Lebrun, R., Adaci, M., Bensalah, M., Fabre, P.-H., Fara, E., Gomes Rodrigues, H., Hautier, L., Jaeger, J.-J., Lazzari, V., Mebrouk, F., Peigné, S., Sudre, J., Tafforeau, P., Valentin, X., Mahboubi, M., 2009. Anthropoid versus strepsirhine status of the African Eocene primates Algeripithecus and Azibius: craniodental evidence. Proc. R. Soc. B. $276,4087-4094$.

Tattersall, I., Schwartz, J.H., 1983. A revision of the European Eocene primate genus Protoadapis and some allied forms. Amer. Mus. Novitates 2762, 1-16.

Thalmann, U., 1994. Die Primaten aus dem eozäen Geiseltal bei Halle/Saale (Deutschland). Cour. Forsch.-Inst. Seckenberg 175, 1-161.

Thalmann, U., Haubold, H., Martin, R.D., 1989. Pronycticebus neglectus - an almost complete adapid primate specimen from the Geiseltal (GDR). Palaeovertebrata 19, 115-130.

Visualization Sciences Group, 2009. AVIZO, Version 6.0. Burlington: Mercury Computer Systems.

Williams, B.A., Kay, R.F., Kirk, E.C., Ross, C.F., 2010. Darwinius masillae is a strepsirrhine - a reply to Franzen et al. (2009). J. Hum. Evol. 59, 574-579.

Winchester, J.M., Boyer, D.M., St. Clair, E.M., Gosselin-Ildari, A.D., Cooke, S.B., Ledogar, J.A., 2014. Dental topography of platyrrhines and prosimians: convergences and contrasts. Am. J. Phys. Anthropol. 153, 29-44. 


\section{Figure and supplementary file captions}

Figure 1. Scatter plots showing that astragalar and calcaneal dimensions of the material attributed to $A$. frontanyensis match the size expected considering $\mathrm{m} / 2$ size of this species and that these postcranials can be assigned to Adapis sp. or $P$. pyrenaicus, the two other primate species found in SJF-3C (Following Boyer and Seiffert (2013), Boyer et al. (2013) and Winchester et al. (2014)): A) Scatter plot of astragalar trochlear width vs. m/2 length; B) Scatter plot of calcaneal cuboid facet area vs. $\mathrm{m} / 2$ length. The primate sample includes different strepsirrhines, Tarsius and Teilhardina. 95\% prediction intervals are represented by dotted lines.

Figure 2. Astragalus and calcaneus of $A$. frontanyensis in dorsal, plantar, lateral, medial, proximal and distal view (from left to right). All scanned specimens included. Astragali: IPS-7712 (left), IPS-7713 (left), IPS-7750 (right), IPS-7796 (right). Calcanei: IPS-7745 (left), IPS-7748 (right), IPS-7749 (right), IPS-7751 (right), IPS-7798 (right), IPS-7799 (left), IPS-7801 (right), IPS-7984 (left), IPS-7986 (left), IPS-7987 (left). Specimens IPS-7750, 7796, 7745, 7799, 7984, 7986 and 7987 are reversed for comparison purposes.

Figure 3. Measurements used for comparisons of $A$. frontanyensis and other genera. For the astragali: A) Total astragalar length; B) Body length; C) Body width; D) Trochlear width; E: Neck length; F: Neck angle; G) Ectal facet length; H) Ectal facet width; I) Sustentacular facet length; J) Sustentacular facet maximum width; K) Sustentacular facet width at contact with navicular facet; L) Body height from medial side; M) Plantar inclination of the neck; N) Head length; O) Head height. Astragalus in dorsal view is oriented so that the trochlear groove runs proximodistally. N and O follow Gebo et al. (1991); A, G, H, I, J and K follow Boyer et al. (2010); C, F, G, H, L, M, O follow Marivaux et al. (2011). For the calcanei: P) Total calcaneal length; Q) Distal calcaneal length; R) Proximal calcaneal length; S) Calcaneal width; T) Ectal facet length; U) Ectal facet width; V) Proximal angle (inclination of the proximal part of the calcaneus); W) Distal calcaneal height; X) Middle calcaneal height (height between ectal and sustentacular facets); Y) Height at ectal facet; Z) Proximal calcaneal height; AA) Cuboid facet length; AB) Cuboid facet height; AC) Proximal facet height; AD) Proximal facet width. S follows Gebo et al. (1991); P, Q, S, T, U, AA and AB follow Gladman et al. (2013).

Figure 4. Most complete astragalar and calcaneal specimens of $A$. frontanyensis in dorsal, plantar, lateral, medial, proximal and distal view (from left to right and top to bottom): A) Left 
astragalus (IPS-7712), B) Left astragalus (IPS-7713); C) Right calcaneus (IPS-7748) except for cuboid facet (distal view) which corresponds to specimen IPS-7745 (left calcaneus, reversed). Arrow 1 shows the presence of a transverse rim of bone on the dorsolateral part of the neck, where it joins the trochlea; arrow 2 shows the presence of a protuberance on the medioplantar side of the medial tibial facet that projects medially.

Figure 5. Box plots of astragalar indices comparing $A$. frontanyensis with other genera. Shaded area shows range of $A$. frontanyensis' measurements. Measurements used for indices correspond to those in figure 3: Body length (B); Total astragalar length (A); Body width (C); Neck length (E); Neck angle (F); Body height (L); Trochlear width (D); Head length (N); Head height (O); Sustentacular facet length (I); Both sustentacular facet widths (J and K);Ectal facet length (G); Ectal facet width $(H)$.

Figure 6. Comparison of different astragali scaled to same trochlear length. Specimens of Notharctus tenebrosus, Asiadapis cambayensis, Djebelemur martinezi, Cheirogaleus medius, Mirza coquereli, Omomys carteri, Necrolemur antiquus and Eosimias sinensis are reversed for comparison purposes. Arrow 1 points to trochlear shelf of the astragalus directed laterally in some specimens or genera; arrow 2 shows the presence of a "bulge" on the lateral side of the trochlear shelf; arrow 3 indicates the presence of a squatting facet; and arrow 4 indicates a medial projection of the plantar margin.

Figure 7. Comparison of different calcanei scaled to same proximal and ectal facet length. Specimens of Microcebus murinus, Teilhardina belgica, Necrolemur zitteli and Eosimias sinensis are reversed for comparison purposes. Arrows point to the distal protrusion of the dorsomedial side of the proximal end of the tuber calcanei in some genera.

Figure 8. Box plots of calcaneal indices comparing $A$. frontanyensis with other genera. Shaded area shows range of $A$. frontanyensis' measurements. Measurements used for indices correspond to those in figure 3: Distal calcaneal length (Q); Total calcaneal length (P); Ectal facet length (T); Proximal calcaneal length (R); Proximal calcaneal height (Z); Ectal facet width (U); Height at ectal facet (Y); Middle calcaneal height (X); Proximal angle (V); Cuboid facet length (AA); Cuboid facet height (AB). 
Figure 9. Dotted lines illustrate the variation of the sustentacular facet. Dashed lines illustrate the navicular facet in the specimens where it is clear. A: Anchomomys frontanyensis (IPS7748), with no distinct distal sustentacular facet; B: Mirza coquereli (DPC 1139) with no distinct distal sustentacular facet; C: Microcebus murinus (AMNH 185629) with no distinct distal sustentacular facet and a navicular facet that is tubercle-like; D: Notharctus tenebrosus (AMNH 129382) with separate proximal and distal sustentacular facets; E: Cheirogaleus medius (DPC 0142) with eight-shaped sustentacular facet and a navicular facet distal to that. Calcaneus of Microcebus murinus reversed for comparison purposes.

Figure 10. Consensus trees derived from parsimony and Bayesian analyses of the 391 character, 106 taxon morphological data matrix. A) Strict consensus of four equally parsimonious trees (following re-rooting, tree length $(T L)=4264$, consistency index $(\mathrm{Cl})=$ 0.1644 , retention index $(\mathrm{RI})=0.5659)$ recovered by 10,000 heuristic search replicates in PAUP 4.10b10, with re-acquisition of previously lost premolars not allowed. Unambiguous synapomorphies supporting node 1 are provided in SOM Table 4) Strict consensus of two equally parsimonious trees $(T L=4239$, consistency index $(\mathrm{Cl})=0.1654$, retention index $(\mathrm{RI})=$ 0.5551 ) recovered by 10,000 heuristic search replicates in PAUP 4.10b10, with re-acquisition of previously lost premolars allowed. Unambiguous synapomorphies supporting nodes 1, 2, and 3 are provided in Table S5. C) "Allcompat" consensus tree (majority-rule tree plus compatible groups) derived from 50 million MCMC generations in MrBayes 3.2.2, the first $25 \%$ of which were discarded as "burn-in" (the chains fully converged, as indicated by a very low $(\sim 0.003)$ average standard deviation of split frequencies on the final generation). While the tree is fully resolved, note that not all clades are supported by high posterior probabilities (e.g., (Azibiidae, (Djebelemur, (Plesiopithecus, crown Strepsirrhini))) supported a posterior probability of only 0.29).

SOM Figure 1. A) IPS-7713 (left astragalus) in dorsal, plantar, lateral, medial, proximal and distal view (from left to right and top to bottom) showing different structures discussed in the text: astragalar body, astragalar neck, astragalar head, groove for tendon of flexor fibularis, lateral tibial facet, transverse rim on neck, neck tubercle, lateral astragalar process, ectal facet, sustentacular facet, astragalar sulcus, spring ligament facet, navicular facet, posterior trochlear shelf, fossa for posterior talofibular ligament, fibular facet, medial tibial facet, fibular facet, trochlear groove, trochlear rims; B) IPS-7748 (right calcaneus) in dorsal, plantar, lateral, medial 
and proximal view (from left to right), and IPS-7745 (left calcaneus, reversed) in distal view showing different structures discussed in the text: distal part, proximal part or tuber calcanei, sustentacular facet, ectal facet, groove for tendon of peroneus longus, groove for tendon of peroneus brevis, peroneal tubercle, distal plantar tubercle, groove for tendon of flexor fibularis, proximal facet, cuboid facet, articular pit of the cuboid facet.

SOM Figure 2. Strict consensus of eight equally parsimonious trees derived from parsimony analysis of the 391 character, 106 taxon matrix in PAUP 4.0b10, with no postcranial characters scored for Anchomomys frontanyensis. Following re-rooting, tree length $=4252.5$, consistency index $=0.1648$, retention index $=0.5663$.

SOM File 1. Nexus file used for phylogenetic analyses.

SOM File 2. Constraint tree file used for phylogenetic analyses. 
Table 1. Astragali and calcanei attributed to Anchomomys frontanyensis and used in this study with information about each specimen and scanning details.

\begin{tabular}{|c|c|c|c|c|c|c|c|c|c|}
\hline ecimen & & Side & MoSo media & & File type & File size & x res* & $y$ res & $\mathrm{z}$ res \\
\hline IPS-7712 & Astragalus & Left & M6345-6065 & doi:10.17602/M2/M6065 & Ply, mesh file & $8.02 \mathrm{MB}$ & $0.0085 \mathrm{~mm}$ & $0.0085 \mathrm{~mm}$ & $0.0085 \mathrm{~mm}$ \\
\hline IPS-7713 & Astragalus & Left & M6346-6066 & $\underline{\text { doi:10.17602/M2/M6066 }}$ & Ply, mesh file & $11.2 \mathrm{MB}$ & $0.0065 \mathrm{~mm}$ & $0.0065 \mathrm{~mm}$ & $0.0065 \mathrm{~mm}$ \\
\hline IPS-7750 & Astragalus & Right & M6347-6067 & doi:10.17602/M2/M6067 & Ply, mesh file & $10.66 \mathrm{MB}$ & $0.0091 \mathrm{~mm}$ & $0.0091 \mathrm{~mm}$ & $0.0091 \mathrm{~mm}$ \\
\hline-7796 & Astragalus & Right & M63 & $2 / \mathrm{M} 6068$ & Ply, mesh file & & $0.0091 \mathrm{~mm}$ & $0.0091 \mathrm{~mm}$ & $091 \mathrm{~mm}$ \\
\hline & Calcaneus & Left & M634 & 2/M6069 & Ply, me & & & $0.0093 \mathrm{~mm}$ & \\
\hline IPS-7748 & Calcaneus & Right & M6350-6070 & 602/M2/M6070 & Ply, mesh file & MB & $0.0079 \mathrm{~mm}$ & $0.0079 \mathrm{~mm}$ & $0.0079 \mathrm{~mm}$ \\
\hline & & Right & & & & & & & $3 \mathrm{~mm}$ \\
\hline IPS-7751 & Calc & Right & M63 & 602/M2/M6072 & h file & MB & $0.0079 \mathrm{~mm}$ & $0.0079 \mathrm{~mm}$ & $0.0079 \mathrm{~mm}$ \\
\hline IPS-7798 & Calcaneus & Right & 5073 & M6073 & file & $8 \mathrm{MB}$ & $0.0099 \mathrm{~mm}$ & $0.0099 \mathrm{~mm}$ & $0.0099 \mathrm{~mm}$ \\
\hline IPS-7799 & Calcaneus & Left & M6355-6074 & doi:10.17602/M2/M6074 & Ply, mesh file & $12.42 \mathrm{MB}$ & $0.0099 \mathrm{~mm}$ & $0.0099 \mathrm{~mm}$ & $0.0099 \mathrm{~mm}$ \\
\hline IPS-7801 & Calcaneus & Right & M6356-6075 & doi:10.17602/M2/M6075 & Ply, mesh file & & $0.0091 \mathrm{~mm}$ & $0.0091 \mathrm{~mm}$ & $0.0091 \mathrm{~mm}$ \\
\hline & & Left & & & & & $0.0079 \mathrm{~mm}$ & $0.0079 \mathrm{~mm}$ & \\
\hline & & Left & & & & & & & \\
\hline IPS-7987 & Calcaneus & Left & M6359-6078 & doi:10.17602/M2/M6078 & Ply, mesh file & $5.97 \mathrm{MB}$ & $0.0099 \mathrm{~mm}$ & $0.0099 \mathrm{~mm}$ & $0.0099 \mathrm{~mm}$ \\
\hline
\end{tabular}

*res $\mathrm{x}, \mathrm{y}, \mathrm{z}$ gives dimensions of 3D pixels in millimeters generated by the raw microCT scans

Locality of all specimens: Sant Jaume de Frontanyà-3C

Age: Middle Eocene, Robiacian (MP14-15)

Scanning facility and scanner: Duke SMIF/Nikon XTH 225 ST

Repository Institution for physical specimens: Institut Català de Paleontologia Miquel Crusafont (ICP), Sabadell

Copyright holder: Institut Català de Paleontologia Miquel Crusafont (ICP), Sabadell, Barcelona

Copyright License: Attribution-NonCommercial CC BY-NC - reuse but noncommercial

Copyright Permission: Permission to use media on MorphoSource granted by copyright holder

Citation instructions: Please cite DOI and specimen number of any files used from this table. Please Cite this paper. Finally, include the following statement in acknowledgments: "Judit Marigó provided access to these data originally appearing in, the collection of which was funded by CGL2014-54373-P, financed by Ministerio de Economía y Competitividad (Spanish Government); 2014 SGR 416 GRC and 2014/100604 financed by Generalitat de Catalunya (Catalan Government), and NSF BCS 1317525. The files were downloaded from www.MorphoSource.org, Duke University" 
Table 2. Astragalar measurements and indices of Anchomomys frontanyensis following Boyer et al. (2010), Marivaux et al. (2011) and Boyer and Seiffert (2013)

Astragalar measurements following Boyer et al. (2010)

\begin{tabular}{lccccc} 
& IPS-7712 & IPS-7713 & IPS-7750 & IPS-7796 & MEAN \\
\cline { 2 - 6 } $1(\mathrm{~mm})$ & 6.98 & 7.06 & - & - & 7.02 \\
$2(\mathrm{~mm})$ & 4.16 & 4.48 & - & - & 4.32 \\
$3(\mathrm{~mm})$ & 2.61 & 2.46 & - & - & 2.53 \\
$4(\mathrm{~mm})$ & 2.27 & 2.16 & 2.18 & 2.14 & 2.19 \\
$5(\mathrm{~mm})$ & 2.75 & 2.93 & 2.76 & 2.53 & 2.74 \\
$6(\mathrm{~mm})$ & 3.38 & 3.46 & 3.17 & 3.17 & 3.29 \\
$7(\mathrm{~mm})$ & 2.14 & 2.44 & - & - & 2.29 \\
$8(\mathrm{~mm})$ & 2.12 & 2.10 & 2.18 & - & 2.13 \\
$9(\mathrm{~mm})$ & 4.23 & 3.95 & - & - & 4.09 \\
$10(\mathrm{~mm})$ & 2.84 & 2.90 & 2.78 & - & 2.84 \\
$11(\mathrm{~mm})$ & 1.09 & 1.25 & 1.10 & - & 1.15 \\
$12(\mathrm{~mm})$ & 1.36 & 1.61 & 1.31 & - & 1.43 \\
$13(\mathrm{~mm})$ & 1.07 & 1.08 & 1.00 & - & 1.05 \\
$14(\mathrm{~mm})$ & 3.05 & 2.53 & - & - & 2.79 \\
$15(\mathrm{~mm})$ & 1.48 & 1.22 & - & - & 1.35 \\
$16(\mathrm{~mm})$ & 1.01 & 1.23 & - & - & 1.12 \\
$17(\mathrm{~mm})$ & 2.51 & 2.62 & - & - & 2.56 \\
$18(\mathrm{~mm})$ & 1.71 & 1.99 & - & - & 1.85 \\
$19\left(^{\circ}\right)$ & 94.30 & 102.23 & 93.33 & 87.23 & 94.28 \\
$20\left({ }^{\circ}\right)$ & 23.77 & 20.2 & 14.97 & 18.03 & 19.24 \\
$21\left(^{\circ}\right)$ & 77.17 & 81.13 & 81.03 & 78.93 & 79.57 \\
$22\left(^{\circ}\right)$ & 88.03 & 91.6 & 87.37 & 70 & 84.25 \\
$23\left({ }^{\circ}\right)$ & 20.3 & 16.5 & - & - & 18.4 \\
$24\left(^{\circ}\right)$ & 113.03 & 114.87 & 108.70 & 110.13 & 111.68 \\
\hline & & & & &
\end{tabular}

Astragalar measurements following Boyer and Seiffert (2013)

Astragalar measurements following Marivaux et al. (2011)

\begin{tabular}{lccccc} 
& IPS-7712 & IPS-7713 & IPS-7750 & IPS-7796 & MEAN \\
\cline { 2 - 6 } TW $(\mathrm{mm})$ & 3.50 & 3.81 & 3.65 & - & 3.65 \\
MTRW (mm) & 2.08 & 2.28 & 2.12 & 1.97 & 2.11 \\
TRL (mm) & 2.76 & 3.03 & - & - & 2.90 \\
NL $(\mathrm{mm})$ & 3.35 & 3.67 & - & - & 3.51 \\
HW $(\mathrm{mm})$ & 2.53 & 2.62 & - & - & 2.57 \\
TL $(\mathrm{mm})$ & 6.92 & 6.97 & - & - & 6.94 \\
HHT $(\mathrm{mm})$ & 2.00 & 2.15 & - & - & 2.07 \\
MTH (mm) & 3.20 & 3.32 & - & - & 3.26 \\
MTBH (mm) & 2.04 & 2.07 & - & - & 2.06 \\
HT $(\mathrm{mm})$ & 3.01 & 2.93 & 3.02 & - & 2.99 \\
EFL $(\mathrm{mm})$ & 2.93 & 2.93 & 2.98 & - & 2.95 \\
EFW $(\mathrm{mm})$ & 1.58 & 1.59 & 1.71 & - & 1.63 \\
MEFW $(\mathrm{mm})$ & 1.06 & 1.20 & 1.13 & - & 1.13 \\
Neck angle $\left({ }^{\circ}\right)$ & 18.93 & 18.67 & - & - & 18.80 \\
\hline
\end{tabular}

Astragalar indices following Marivaux et al. (2011)

\begin{tabular}{lccccc} 
& IPS-7712 & IPS-7713 & IPS-7750 & IPS-7796 & MEAN \\
\cline { 2 - 6 } NL/TL & 0.48 & 0.53 & - & - & 0.51 \\
NL/TRL & 1.21 & 1.21 & - & - & 1.21 \\
NL/MTRW & 1.61 & 1.61 & - & - & 1.61 \\
HT/MTRW & 1.45 & 1.29 & 1.42 & - & 1.39 \\
HT/TRL & 1.09 & 0.97 & - & - & 1.03 \\
MTRW/TRL & 0.75 & 0.75 & - & - & 0.75 \\
HW/HHT & 1.27 & 1.22 & - & - & 1.24 \\
HW/MTRW & 1.22 & 1.15 & - & - & 1.18 \\
TW/TL & 0.51 & 0.55 & - & - & 0.53 \\
\hline
\end{tabular}

\begin{tabular}{lccccc} 
& IPS-7712 & IPS-7713 & IPS-7750 & IPS-7796 & MEAN \\
\cline { 2 - 6 } FFS $\left({ }^{\circ}\right)$ & 110.86 & 109.49 & 105.02 & - & 108.46 \\
Mtf $\left(\mathrm{mm}^{2}\right)$ & 3.83 & 3.99 & 3.73 & - & 3.85 \\
Ect $\left(\mathrm{mm}^{2}\right)$ & 4.32 & 4.59 & 4.11 & - & 4.34 \\
Troch $(\mathrm{mm})$ & 2.34 & 2.55 & 2.40 & - & 2.43
\end{tabular}


a1: Maximum proximodistal length; 2: Body proximodistal length; 3: Head and neck proximodistal length; 4: Fibular facet maximum dorsoplantar height; 5: Fibular facet proximodistal length; 6: Lateral tibial facet maximum proximodistal length along lateral margin; 7 : Lateral tibial facet maximum mediolateral width; 8: Medial tibial facet maximum dorsoplantar height; 9: Lateral tibial facet maximum proximodistal length along medial margin; 10: Ectal facet proximodistal length; 11: Ectal facet mediolateral width; 12: Flexor fibularis groove mediolateral width; 13: Flexor fibularis groove proximodistal length; 14: Sustentacular facet proximodistal length; 15 :

Sustentacular facet mediolateral width; 16: Sustentacular facet width of contact with navicular facet; 17: Maximum mediolateral diameter of astragalar head; 18: Maximum dorsoplantar height of astragalar head; 19: Angle between fibular facet and lateral tibial facet; 20: Angle between fibular facet and medial tibial facet; 21: Angle between medial and lateral tibial facets; 22: Angle between ectal facet and fibular facet; 23: Angle between major axis of head and plane of lateral tibial facet; 24: Fibular facet slope (following Boyer et al., 2010); FFS: Fibular facet slope; Mtf: Medial tibial facet area; Ect: ectal facet area; Troch: trochlear width (following Boyer and Seiffert, 2013); TL: talar (astragalar) length; NL: talar (astragalar) neck length; TRL: trochlear length; MTRW: midtrochlear width; TW: talar (astragalar) width; MTH: medial talar (astragalar) height; MTBH: medial talar (astragalar) body height; HT: lateral talar (astragalar) body height; HW: talar (astragalar) head width; HHT: talar (astragalar) head height; EFL: maximum ectal facet length; EFW: maximum ectal facet width; MEFW: minimum ectal facet width; $\mathrm{a}^{\mathrm{o}}$ : talar (astragalar) neck angle (following Marivaux et al., 2011, modified after Gebo, 1988, 1989; Gebo et al., 2001; Seiffert and Simons, 2001). 
Table 3. Calcaneal measurements and indices of Anchomomys frontanyensis following Gladman et al. (2013) ${ }^{a}$

Calcaneal measurements following Gladman et al., (2013)

\begin{tabular}{|c|c|c|c|c|c|c|c|c|c|}
\hline & IPS-7745 & IPS-7748 & IPS-7749 & IPS-7751 & IPS-7799 & IPS-7801 & IPS-7984 & IPS-7986 & MEAN \\
\hline CL (mm) & - & 10.90 & - & - & - & - & - & - & 10.90 \\
\hline $\mathrm{CW}(\mathrm{mm})$ & 3.52 & 3.68 & 3.26 & - & - & 3.1 & - & 3.34 & 3.36 \\
\hline DL (mm) & 4.78 & 5.95 & - & - & - & - & - & - & 5.36 \\
\hline PL (mm) & - & 2.16 & - & - & - & - & - & - & 2.16 \\
\hline EFL (mm) & - & 2.80 & 2.52 & 2.25 & - & 2.06 & 2.72 & - & 2.47 \\
\hline $\mathrm{EFW}(\mathrm{mm})$ & - & - & - & 1.18 & - & - & - & - & 1.18 \\
\hline $\mathrm{CFH}(\mathrm{mm})$ & 1.69 & - & - & - & 1.54 & - & - & - & 1.62 \\
\hline $\mathrm{CFW}(\mathrm{mm})$ & 2.32 & - & - & - & 2.25 & - & - & - & 2.29 \\
\hline EFA $\left(\mathrm{mm}^{2}\right)$ & - & - & - & 3.17 & - & - & - & - & 3.17 \\
\hline $\mathrm{CFA}\left(\mathrm{mm}^{2}\right)$ & 3.15 & - & - & - & 2.98 & - & - & - & 3.07 \\
\hline
\end{tabular}

Calcaneal indices following Gladman et al., (2013)

\begin{tabular}{|c|c|c|c|c|c|c|c|c|c|}
\hline & IPS-7745 & IPS-7748 & IPS-7749 & IPS-7751 & IPS-7799 & IPS-7801 & IPS-7984 & IPS-7986 & MEAN \\
\hline CW/CL & - & 0.34 & - & - & - & - & - & - & 0.34 \\
\hline $\mathrm{DL} / \mathrm{CL}$ & - & 0.55 & - & - & - & - & - & - & 0.55 \\
\hline EFW/EFL & - & - & - & 0.52 & - & - & - & - & 0.52 \\
\hline EFL/CL & - & 0.26 & - & - & - & - & - & - & 0.26 \\
\hline $\mathrm{CFW} / \mathrm{CFH}$ & 1.37 & - & - & - & 1.46 & - & - & - & 1.42 \\
\hline
\end{tabular}

${ }^{a}$ CL: calcaneal length; CW: calcaneal width; DL: distal segment length; PL: proximal segment length; EFL: ectal facet length; EFW: ectal facet width; CFH: cuboid facet height; CFW: cuboid facet width; EFA: ectal facet area; CFA: cuboid facet area. 
Click here to download high resolution image

\section{FIGURES}

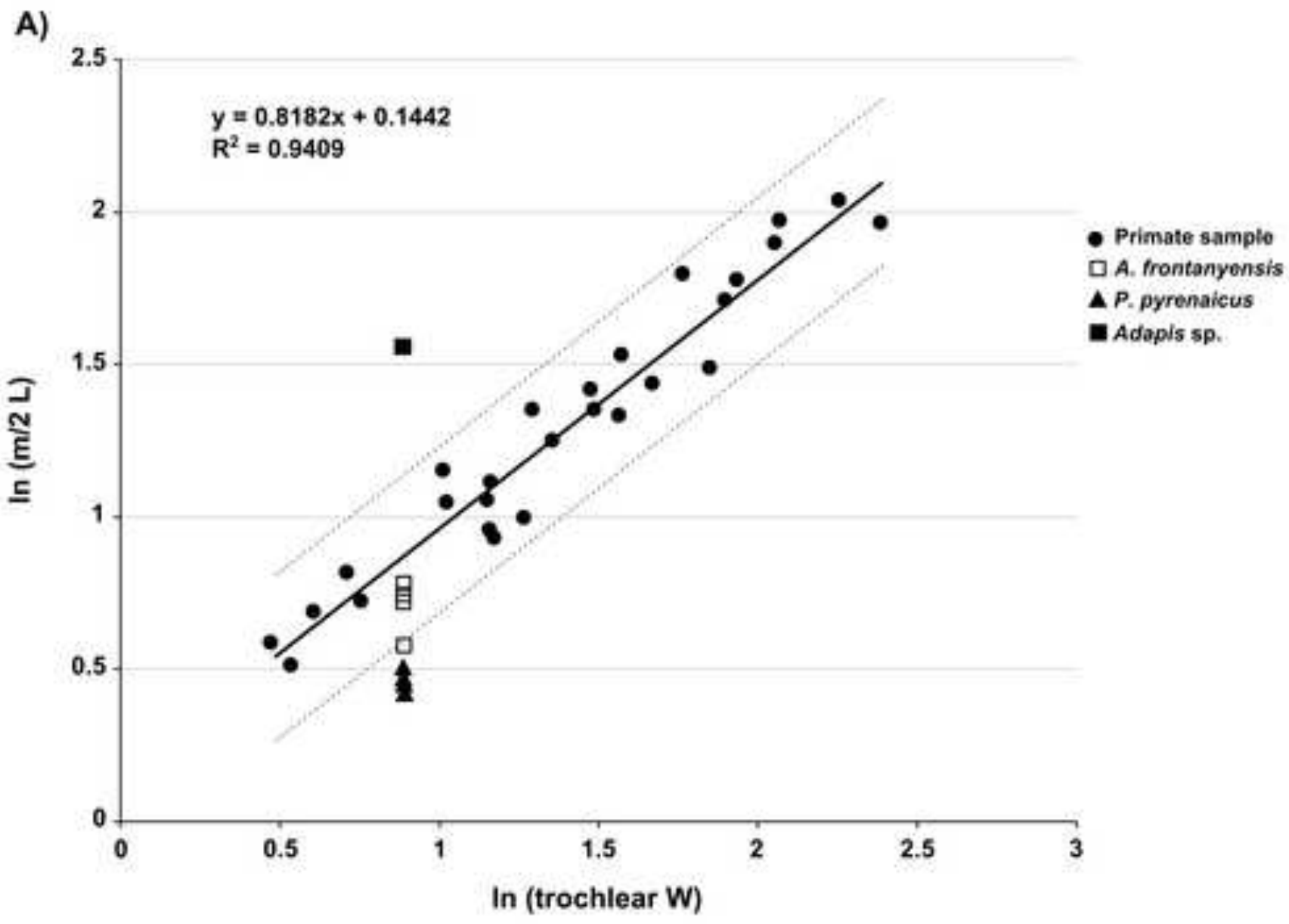

B)

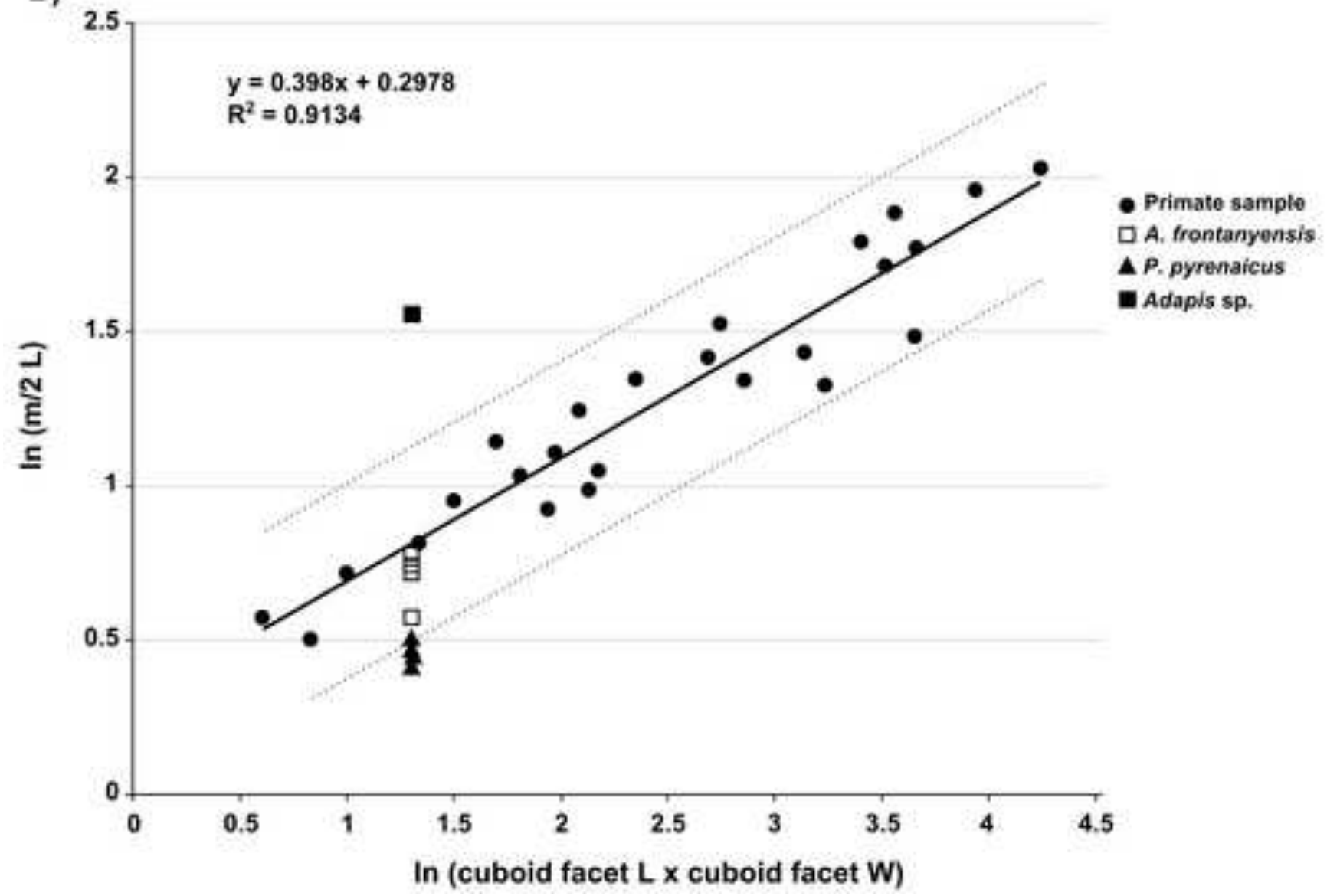




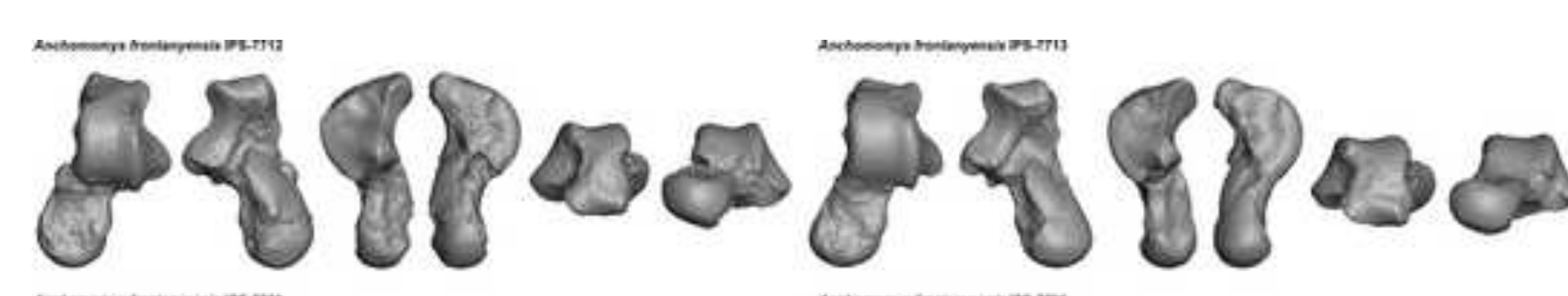

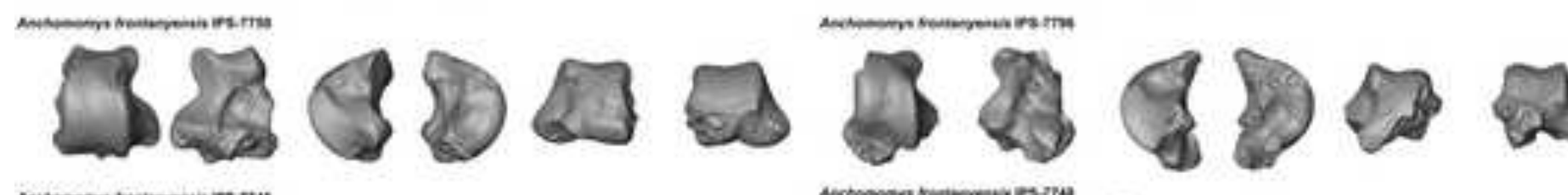

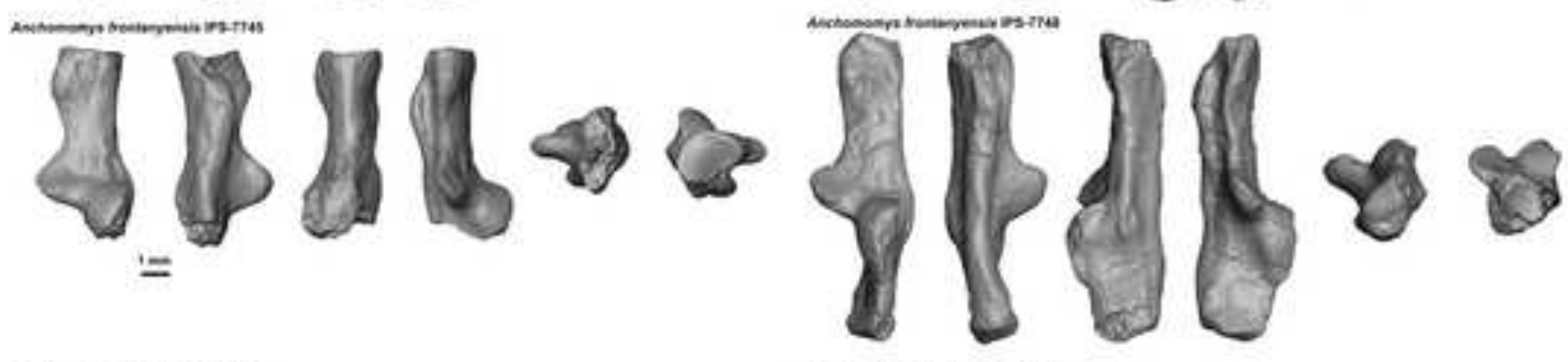
TPABa Vor TP

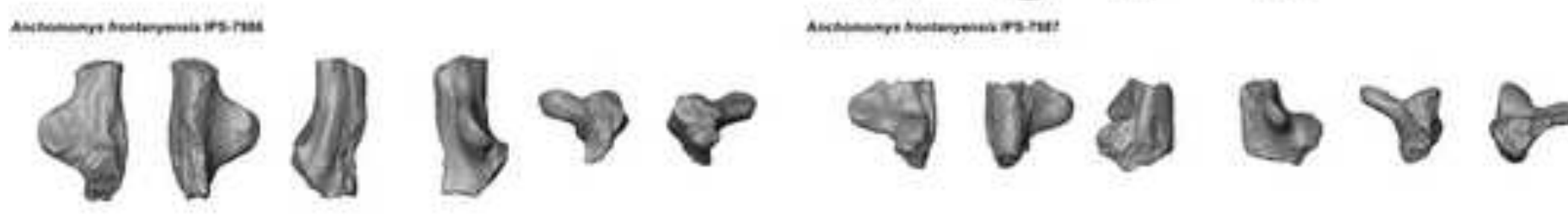


8848

HEA 
Figure 4

Click here to download high resolution image
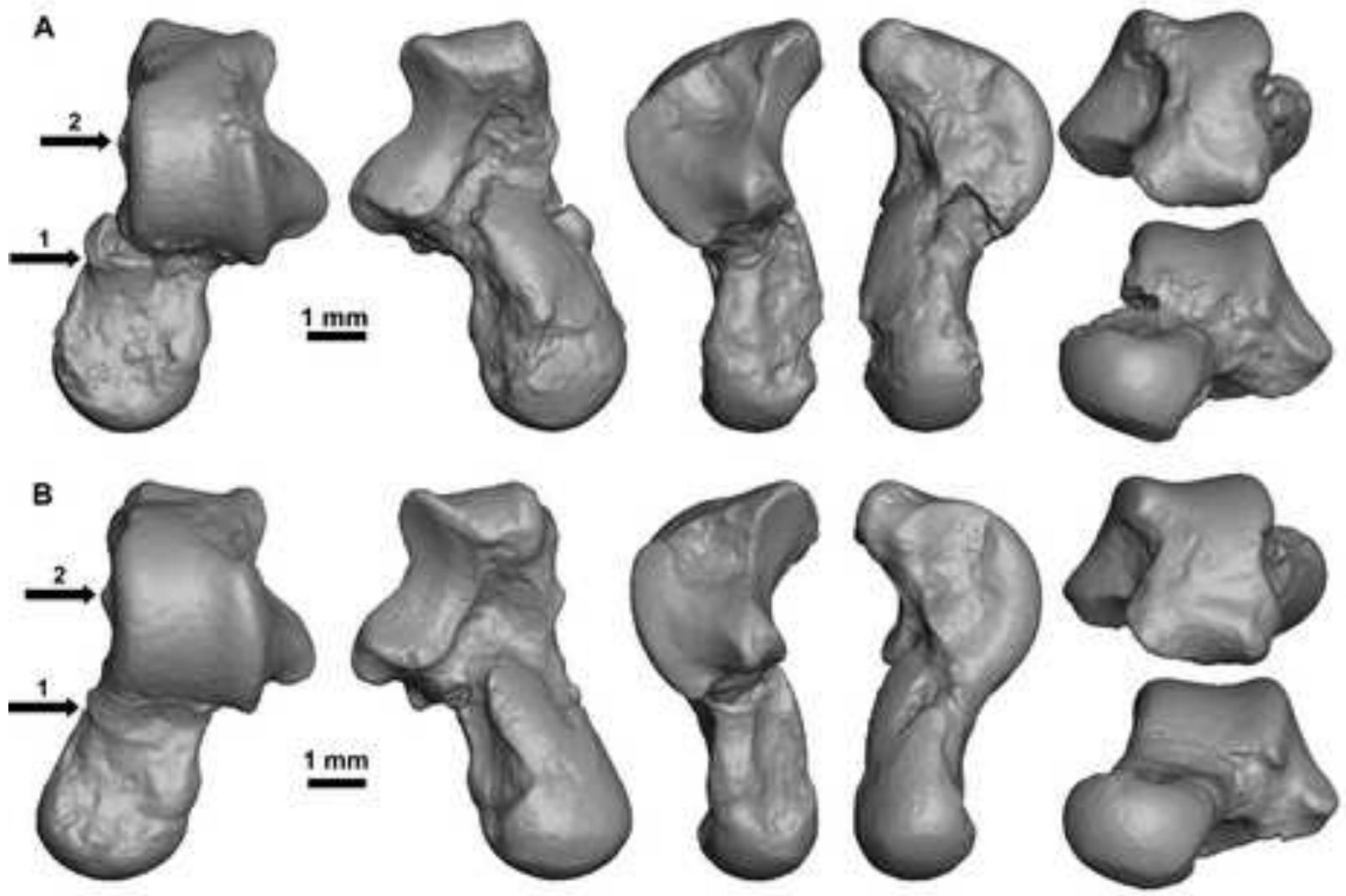

C

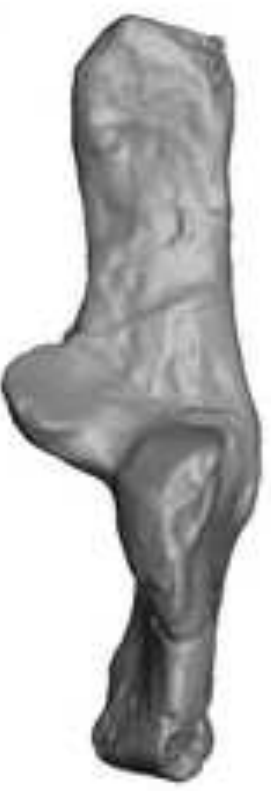

D

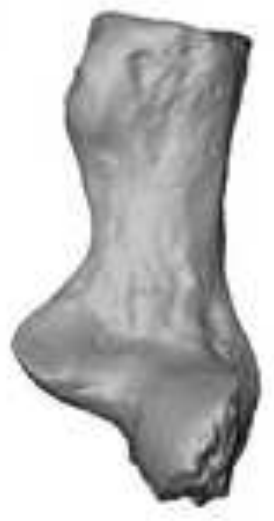

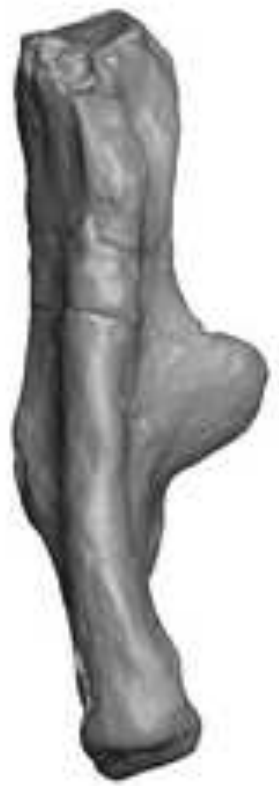
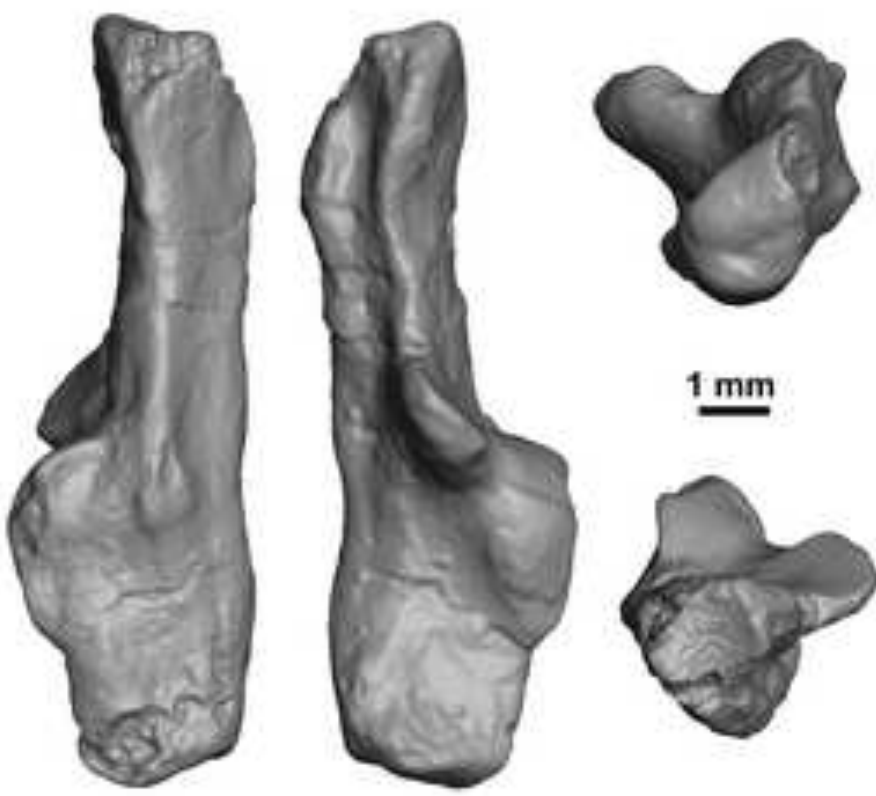

$1 \mathrm{~mm}$
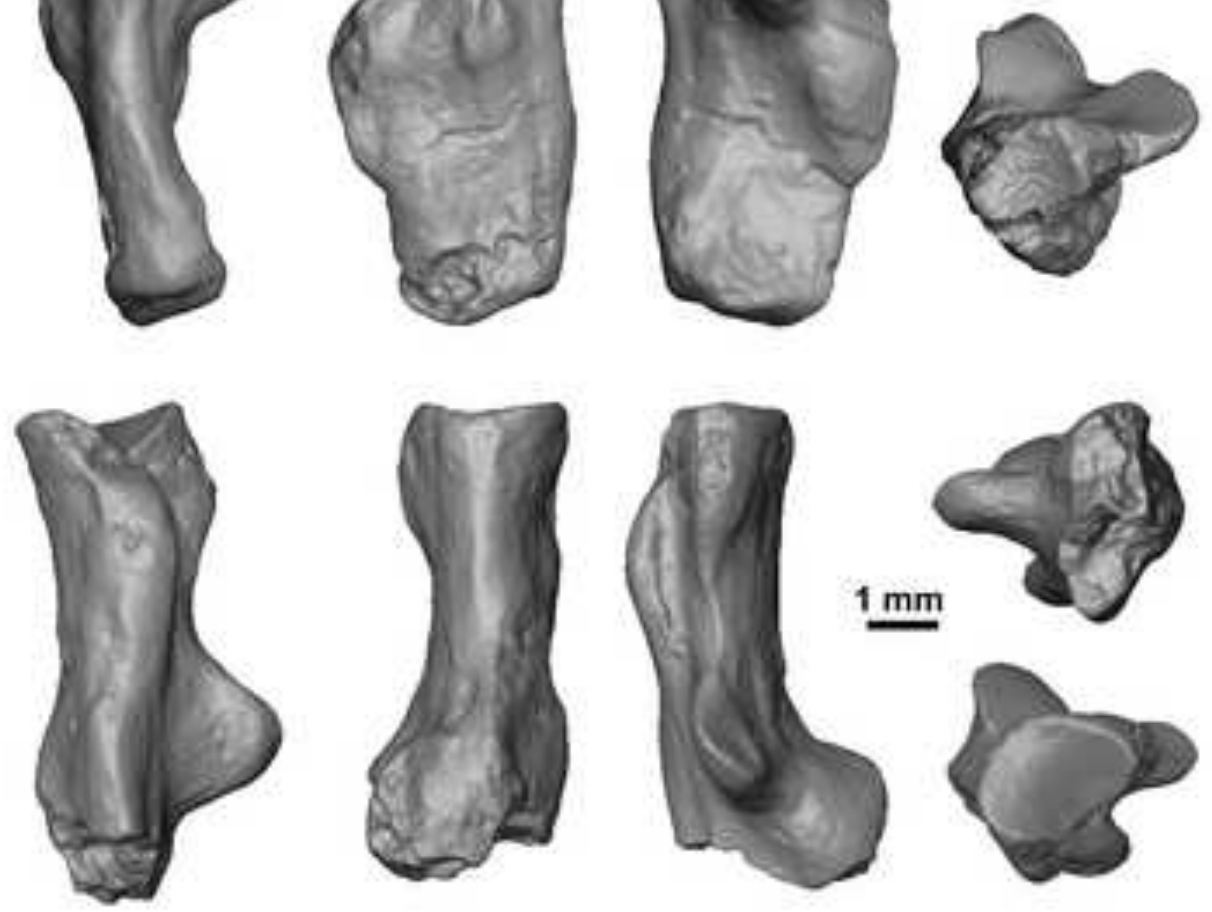


\section{Figure 5}

Click here to download high resolution image

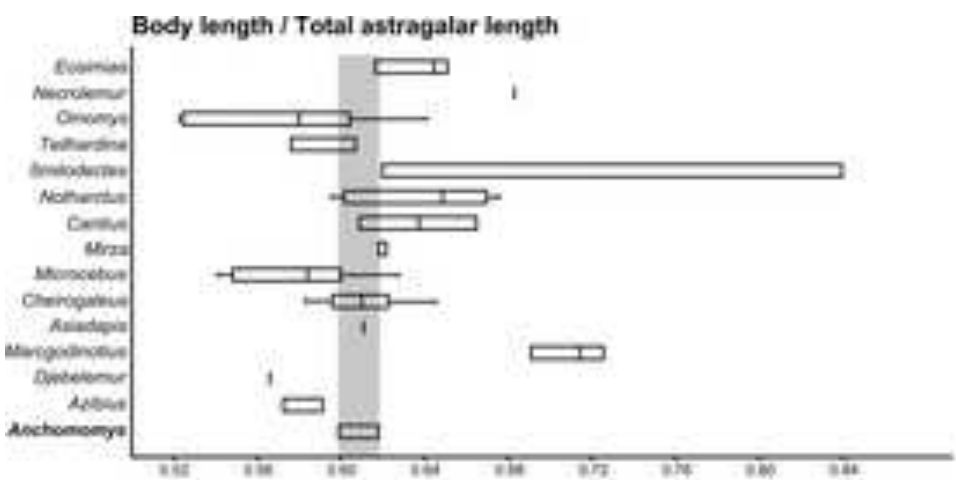

Body widh / Total astragalar length
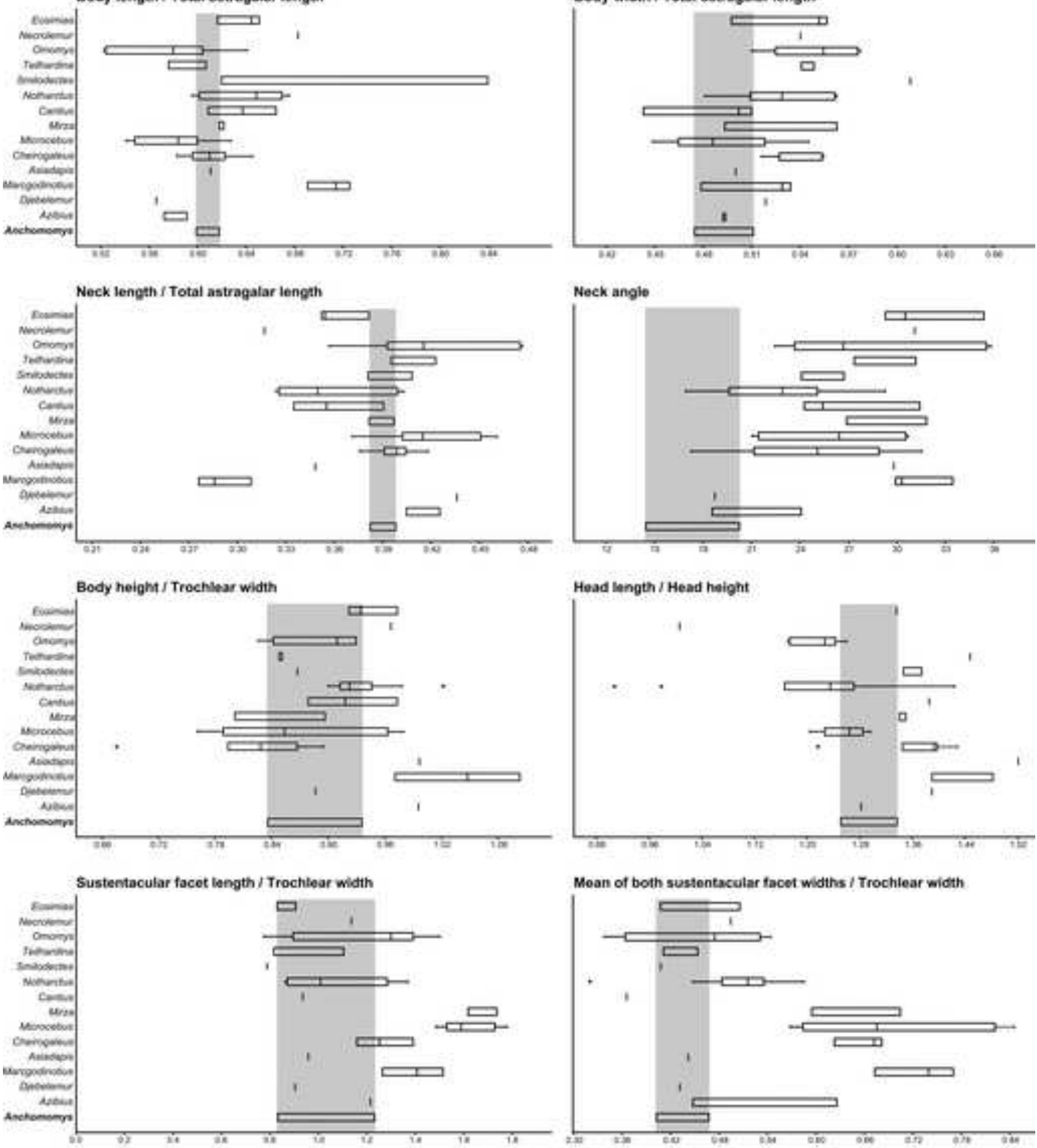

Ectal facet length / Body length
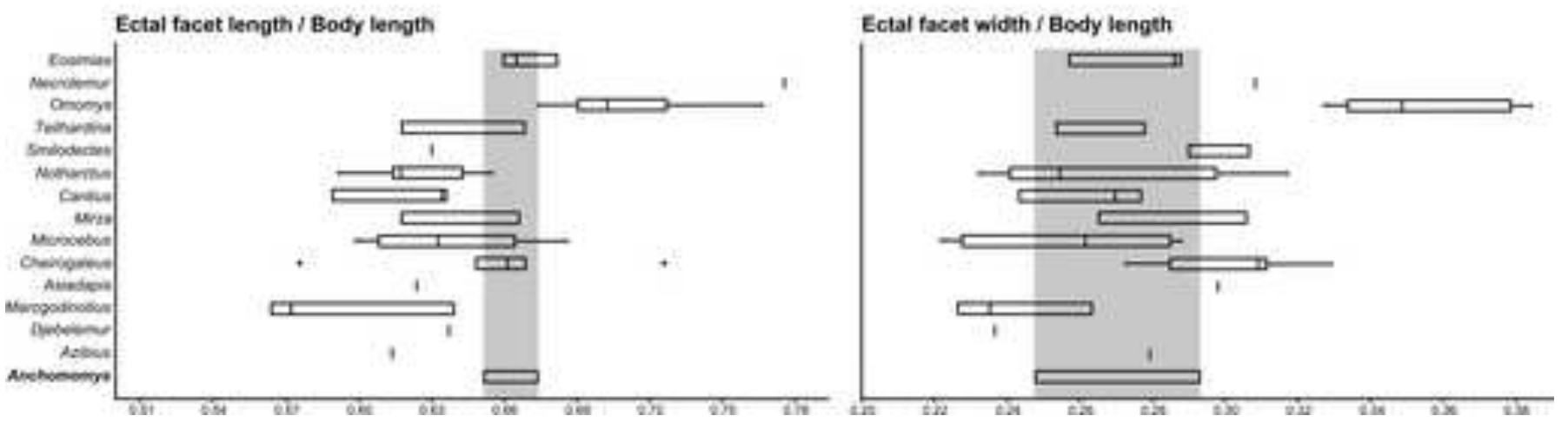
Figure 6

Click here to download high resolution image
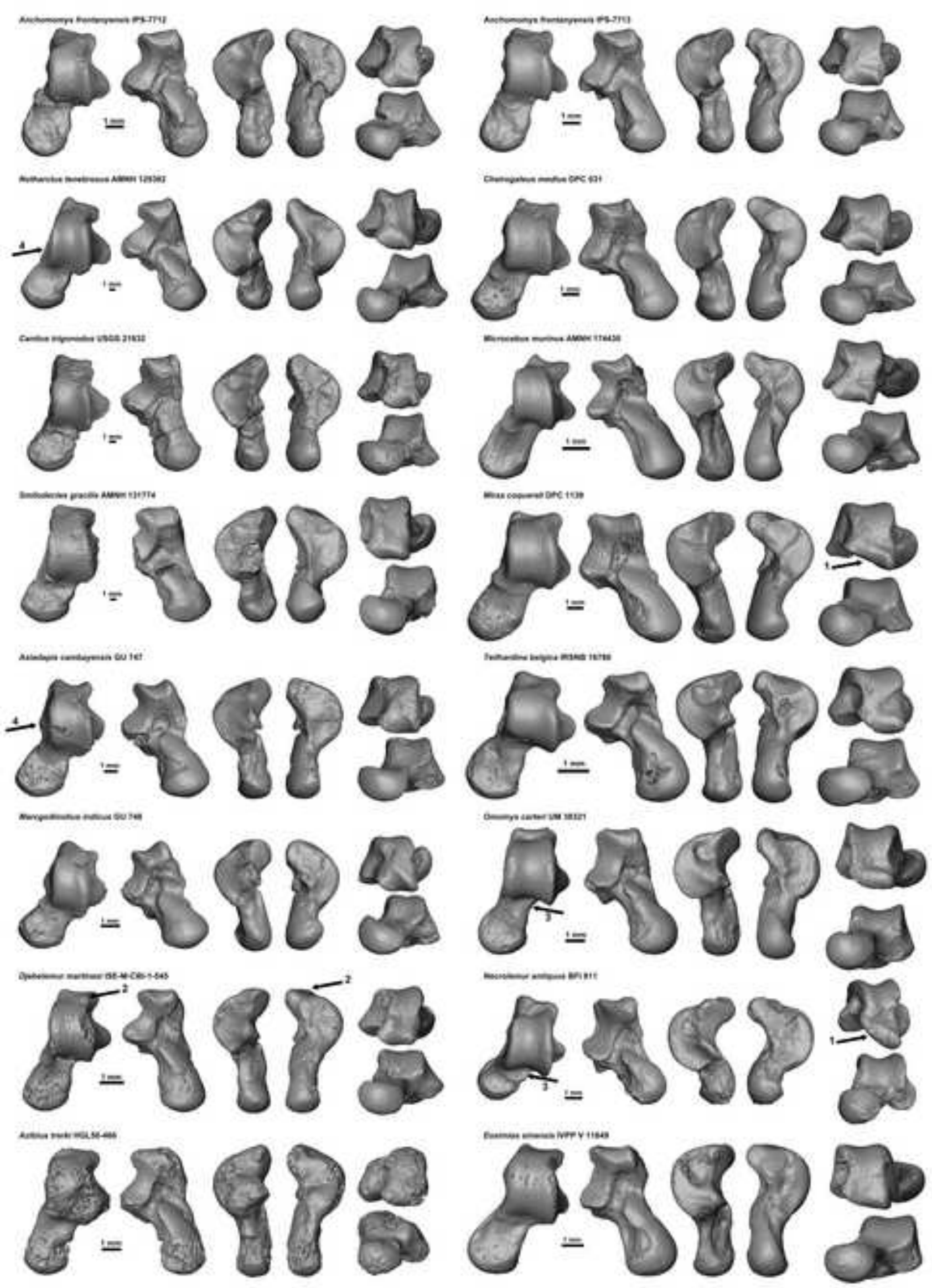
Figure 7

Click here to download high resolution image
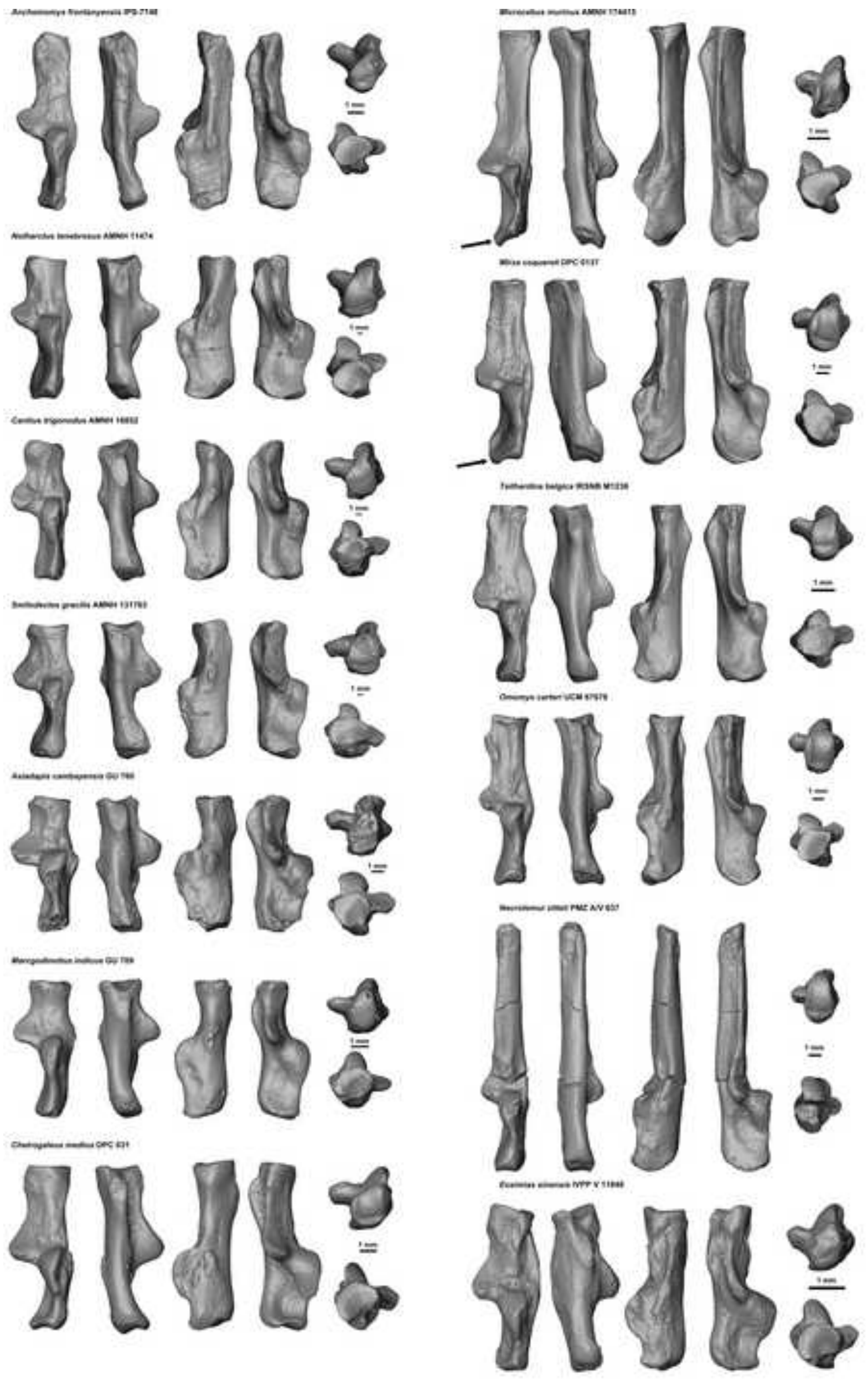


\section{Figure 8}

Click here to download high resolution image
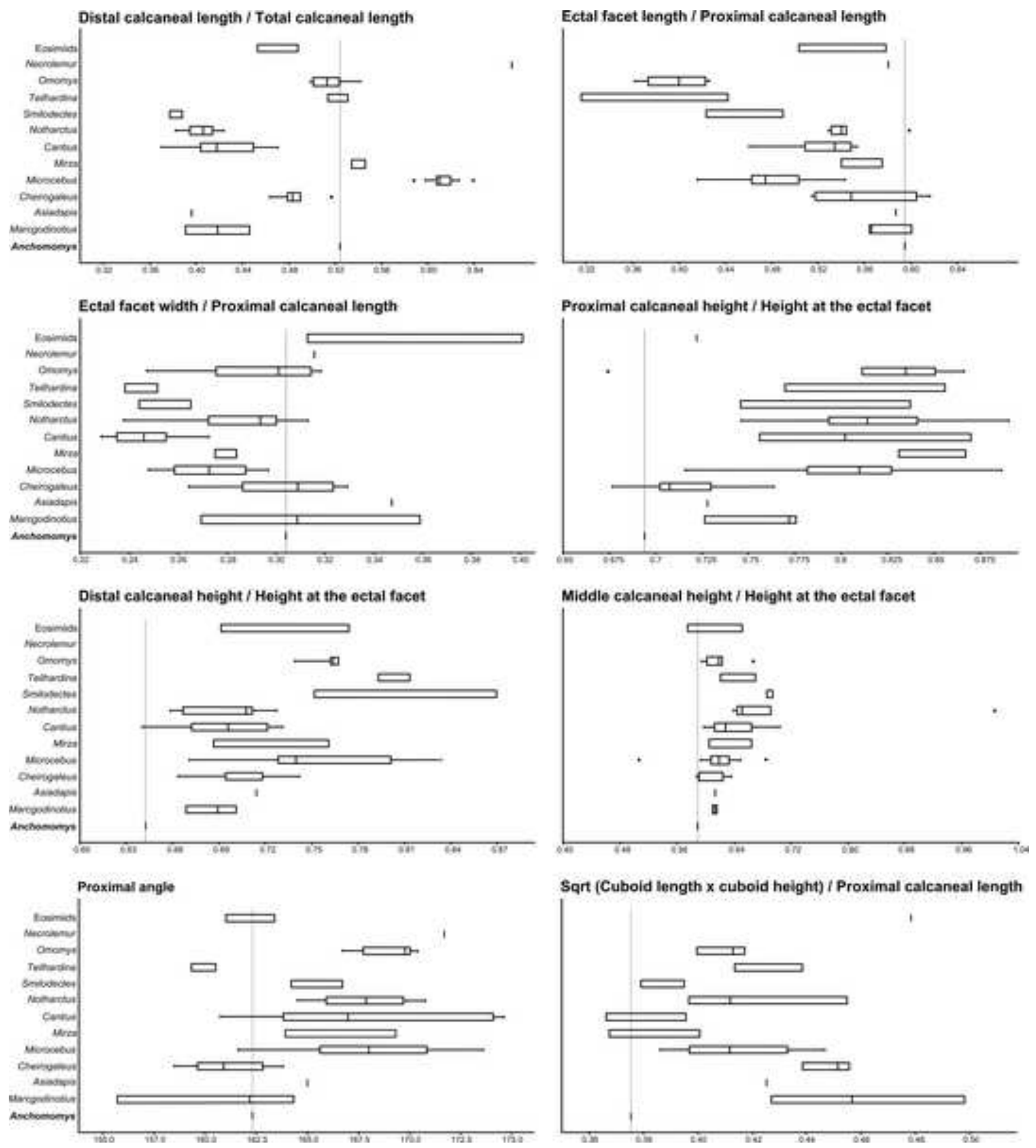

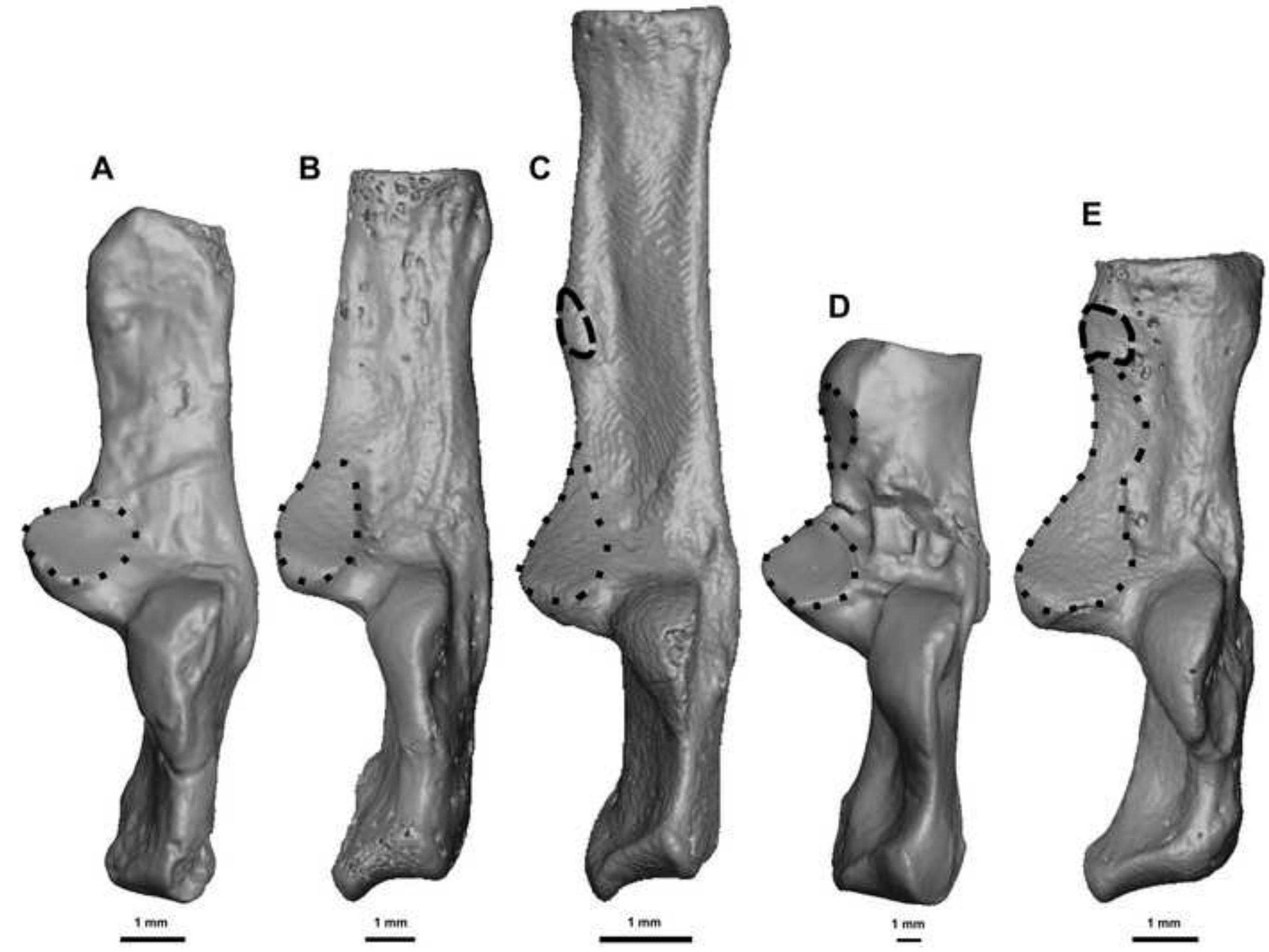

$1 \mathrm{~mm}$

$1 \mathrm{~mm}$ 
ANTHROPOIDEA

-TARSIIFORMES

71-Asiadapis cambayensis

Marcgodinotius indicus

4-Afradapis longicristatus

Laenopithecus lemuroides

1 Europolemur dunaifi

Europolemur klatti

Microadapis scireus

Leptadapis ruetimeye

95 Leptadapis priscus

90_ Adapis parisiensis

- Cantius abditus

Cantius ralstoni

- Pronycticebus gaudryi

Protoadapis curvicuspiden

94 - Hoanghonius stehlini

-Rencunius zhou

-Anchomomys frontanyensis

L Mazateronodon endemicus

- Nievesia sossisensis

96 - Algeripithecus minutus

Azibius trerki

Anchomomys milleri

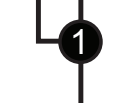

4

- Djebelemur martinezi

-Karanisia clarki

Plesiopithecus teras

89 Cheirogaleus major

83 Microcebus murinus

81 Lepilemur mustelinus

Propithecus spp.

100 Varecia variegata

52 86 - Nycticebus coucang

56 Loris tardigradus

$57 \quad 62$ - Arctocebus calabarensis

57 Saharagalago misrensis

- Wadilemur elegans

Otolemur crassicaudatus Purgatorius unio

- Plesiolestes problematicus

71 Carpolestes simpsoni

${ }_{73}$ L Plesiadapis tricuspidens Tupaia glis

Donrussellia provincialis

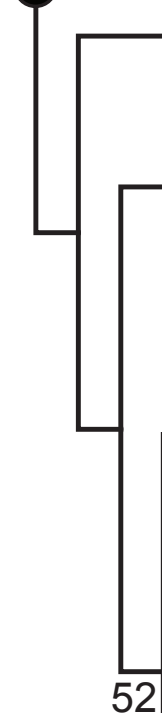

( Anchomomys gallard

66 - Nycticeboides simpsoni

84 Komba spp.

Galagoides demidoff

- Galago moholi
99 Cantius abditus

- Cantius ralstoni

- Donrussellia provincialis

93 Hoanghonius stehlini

Rencunius zhoui

67 Asiadapis cambayensis

Larcgodinotius indicus

90 - Adapis parisiensis

L Leptadapis magnus

95 Leptadapis priscus

62 L Leptadapis ruetimeyer

Aframonius dieides

Afradapis longicristatus

Caenopithecus lemuroides

Europolemur dunaifi

Mahgarita stevensi

Europolemur klatti

- Pronycticebus gaudryi

- Protoadapis curvicuspidens

Microadapis sciureus

- Anchomomys frontanyensis

- Mazateronodon endemicus

L Nievesia sossisensis

- Anchomomys gaillardi

- Algeripithecus minutus

- Azibius trerki

- Anchomomys milleri

- Djebelemur martinezi

Karanisia clark

Plesiopithecus teras

2 Cheirogaleus major

86- Microcebus murinus

78 Lepilemur mustelinus

- Propithecus spp.

77 L Lemur catta

97 Varecia variegata

71-Nycticeboides simpsoni

88 - Nycticebus coucang

58 Loris tardigradus

63-Arctocebus calabarensis

- Perodicticus potto

58 Saharagalago misrensis

Komba spp.

4 Galagoides demidoff

$96-$ Galago moholi

98 Otolemur crassicaudatus

71 Plesiolestes problematicus

C Carpolestes simpson

${ }_{22}$ Plesiadapis tricuspidens

Tupaia glis

Purgatorius unio
C

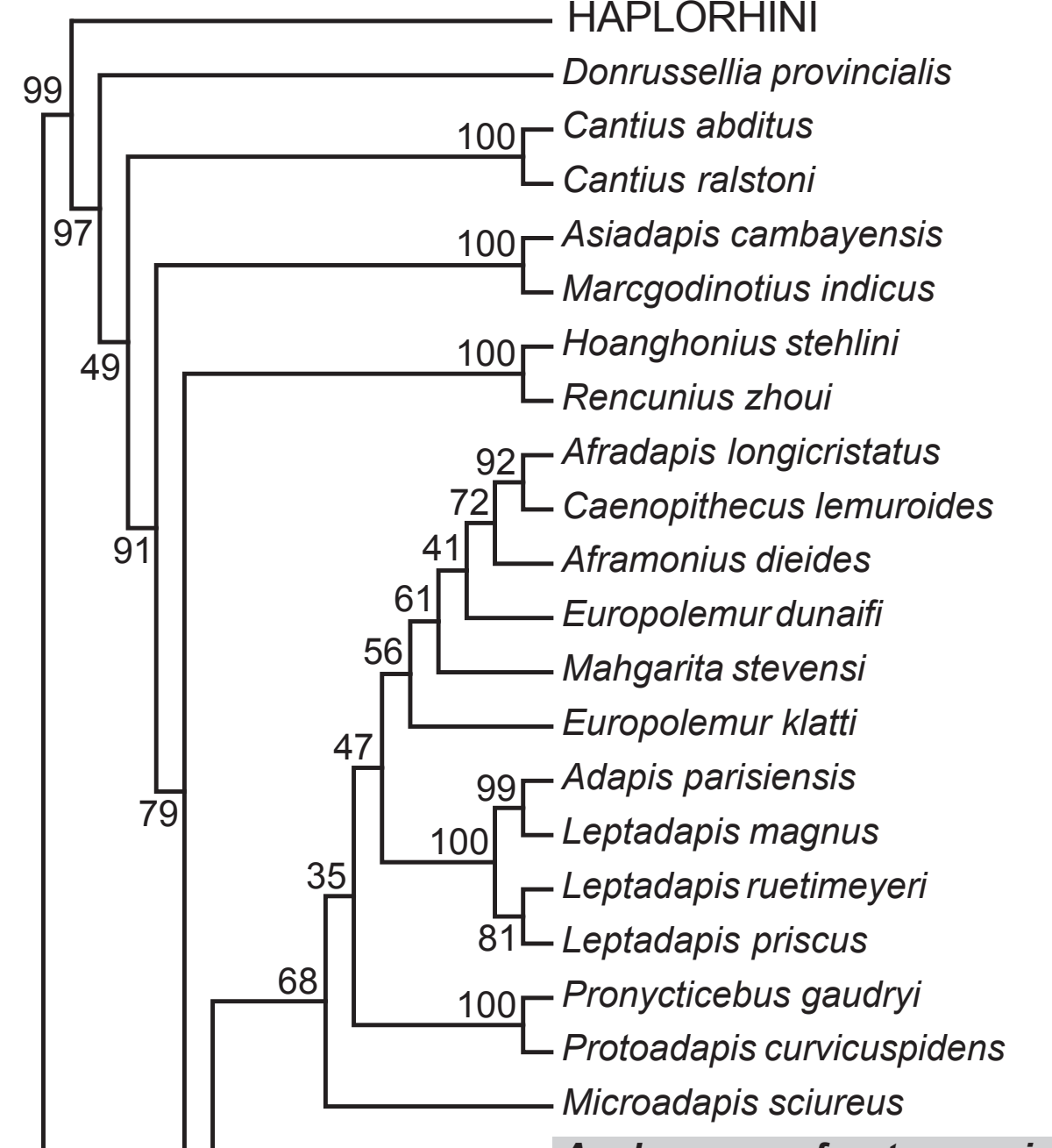

62-Anchomomys frontanyensis

90 Mazateronodon endemicus

$94 \square$ Nievesia sossisensis

Anchomomys gaillardi

100

$100-$ Algeripithecus minutus

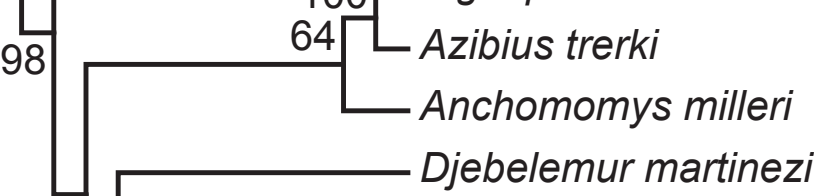

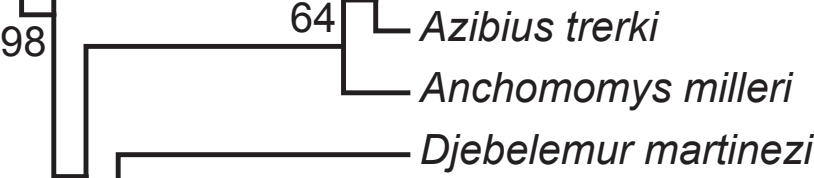

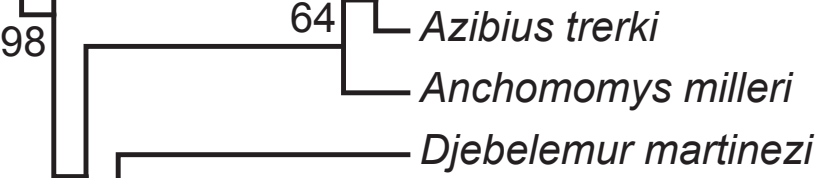

29 Plesiopithecus teras

100 Lepilemur mustelinus

68

Propithecus spp.

100 Lemur catta

99 Varecia variegata

58-Arctocebus calabarensis

47

100158 - Karanisia clarki

59 Lerodicticus potto

82 92 Loris tardigradus

- Nycticebus coucang

Nycticeboides simpsoni

95 Saharagalago misrensis

Komba spp.

$4 9 \longdiv { 4 }$ Wadilemur elegans

58 Galagoides demidoff - Altanius orlovi

94 Plesiolestes problematicus

100 L Plesiadapis tricuspidens Tupaia glis
55100 Cheirogaleus major

100 Galago moholi

100 Otolemur crassicaudatus

- Carpolestes simpsoni 